\title{
A comparative analysis of inhibitors of the glycolysis pathway in breast and ovarian cancer cell line models
}

\author{
Chrysi Xintaropoulou ${ }^{1}$, Carol Ward ${ }^{1}$, Alan Wise ${ }^{2}$, Hugh Marston $^{2,4}$, Arran Turnbull $^{3}$, \\ Simon P. Langdon ${ }^{1}$ \\ ${ }^{1}$ Division of Pathology, Institute of Genetics and Molecular Medicine, University of Edinburgh, Western General Hospital, \\ Edinburgh, EH4 2XU, UK \\ ${ }^{2}$ IOMET Pharma, Nine, Edinburgh BioQuarter, Edinburgh, EH16 4UX, UK \\ ${ }^{3}$ Breakthrough Breast Unit, Institute of Genetics and Molecular Medicine, University of Edinburgh, Western General Hospital, \\ Edinburgh, EH4 2XU, UK \\ ${ }^{4}$ Current Address: Eli Lilly Research and Development, Windlesham, Surrey, GU20 6PH, UK
}

Correspondence to:

Simon P. Langdon, e-mail: Simon.Langdon@ed.ac.uk

Keywords: glycolysis, inhibitors, ovarian cancer, breast cancer

Received: May 12, $2015 \quad$ Accepted: June 29, 2015

Published: July 16, 2015

\section{ABSTRACT}

Many cancer cells rely on aerobic glycolysis for energy production and targeting of this pathway is a potential strategy to inhibit cancer cell growth. In this study, inhibition of five glycolysis pathway molecules (GLUT1, HKII, PFKFB3, PDHK1 and LDH) using 9 inhibitors (Phloretin, Quercetin, STF31, WZB117, 3PO, 3-bromopyruvate, Dichloroacetate, Oxamic acid, NHI-1) was investigated in panels of breast and ovarian cancer cell line models. All compounds tested blocked glycolysis as indicated by increased extracellular glucose and decreased lactate production and also increased apoptosis. Sensitivity to several inhibitors correlated with the proliferation rate of the cell lines. Seven compounds had IC $_{50}$ values that were associated with each other consistent with a shared mechanism of action. A synergistic interaction was revealed between STF31 and Oxamic acid when combined with the antidiabetic drug metformin. Sensitivity to glycolysis inhibition was also examined under a range of $\mathrm{O}_{2}$ levels $\left(21 \% \mathrm{O}_{2}, 7 \% \mathrm{O}_{2}, 2 \% \mathrm{O}_{2}\right.$ and $\left.0.5 \% \mathrm{O}_{2}\right)$ and greater resistance to the inhibitors was found at low oxygen conditions $\left(7 \% \mathrm{O}_{2}, 2 \% \mathrm{O}_{2}\right.$ and $\left.0.5 \% \mathrm{O}_{2}\right)$ relative to $21 \% \mathrm{O}_{2}$ conditions. These results indicate growth of breast and ovarian cancer cell lines is dependent on all the targets examined in the glycolytic pathway with increased sensitivity to the inhibitors under normoxic conditions.

\section{INTRODUCTION}

In the 1920s, Otto Warburg demonstrated that cancer cells exhibit an alteration in their metabolism when compared with non-malignant cells. Normal cells in the presence of oxygen use primarily the mitochondrial tricarboxylic acid (TCA) cycle and oxidative phosphorylation for the production of energy and rely on glycolysis only when their oxygen supply is limited. In contrast, cancer cells frequently utilise glycolysis even in the presence of sufficient amounts of oxygen $[1,2]$. This persistence of aerobic glycolysis in many cancers is now well substantiated and considered a 'hallmark' of advanced cancers [3]. The fact that cancer cells reduce their dependence on mitochondrial oxidative phosphorylation and are more reliant on glycolysis provides a wide range of potential targets for therapy. Targeting aerobic glycolysis is a promising strategy to preferentially kill cancer cells which are dependent on this pathway and in recent years multiple glycolytic inhibitors have been developed [4-6]. However, to date only a few agents have been assessed within in vivo experiments and even fewer have undergone clinical trials [4-6].

The glycolytic pathway comprises a series of ten reactions (Figure 1). All of the enzymes within the glycolysis pathway potentially represent targets for anticancer treatment and inhibitors have been developed that target molecular components of this pathway [4-6] 


\section{Extracellular \\ GLUCOSE}

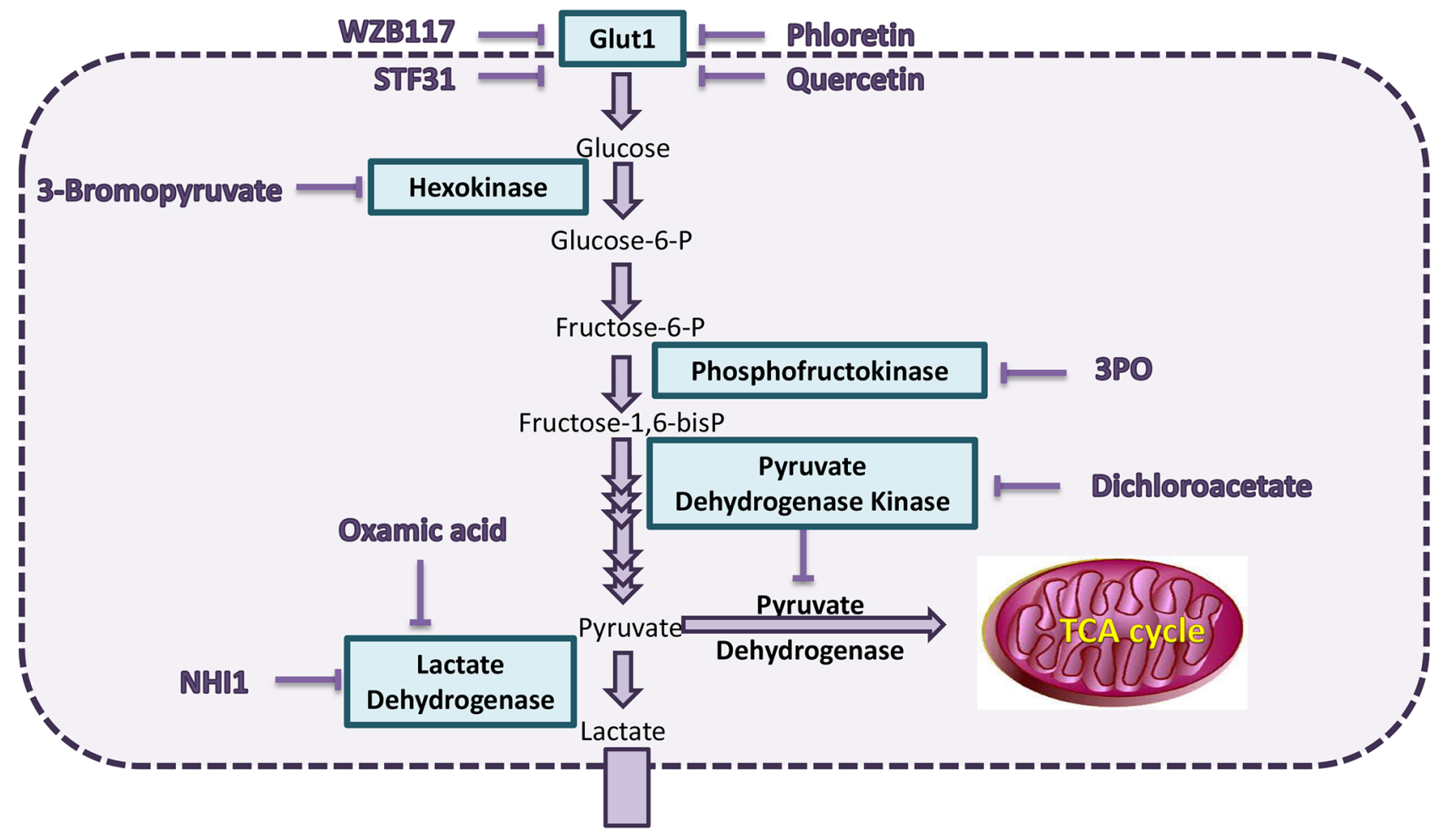

Extracellular LACTATE

Figure 1: Scheme of selected components of the glycolysis pathway and the inhibitors studied. One molecule of glucose is catabolised to two molecules of pyruvate releasing two ATP molecules. Glucose is transported into the cell by the glucose transporter (GLUT) family of molecules and, once inside the cell, is phosphorylated to glucose-6-phosphate (G6P) by hexokinase. After conversion of G6P to fructose-6-phosphate, a second phosphate group is added to fructose-6-phosphate by 6-phosphofructo-1-kinase (PFK1). Several more enzyme reactions eventually produce pyruvate. In normal tissues under aerobic conditions, pyruvate is directed into the mitochondrion by pyruvate dehydrogenase (PDH). Under anaerobic conditions, pyruvate is converted to lactate by lactate dehydrogenase (LDH) and this is also facilitated by the increased activity of pyruvate dehydrogenase kinase 1 (PDHK1), which blocks PDH activity. In malignant cells, this conversion of pyruvate to lactate occurs even under aerobic conditions and has been denoted the Warburg effect.

(Figure 1). Inhibitors of glucose transporter 1 (GLUT1) include the flavonoids Phloretin and Quercetin [7]. Flavonoids are polyphenolic substances, abundantly distributed in plants, fruits and vegetables and are well known for their powerful anti-oxidative and anti-inflammatory effects [8]. Furthermore, they have been shown to inhibit glucose transmembrane transport and proven to have preclinical anticancer activity $[7,8]$. Phloretin, mainly found in the members of the Rosaceae family, has been demonstrated to induce apoptosis in breast cancer cells as well as in hepatocellular carcinoma both in vitro and in vivo $[9,10]$. Quercetin has been shown to induce apoptosis in breast and colon cancer cell lines $[11,12]$. Recently, Chan et al. identified STF31, a compound which induces cell death selectively in VHL-deficient renal cell carcinoma cells by binding specifically to GLUT1 and impairing glucose uptake [13]. WZB117 is a novel specific GLUT1 inhibitor causing suppression of glucose metabolism, inhibition of cellular proliferation both in vitro and in vivo and cell-cycle arrest leading to senescence and necrosis [14].
Inhibitors of hexokinase II include 3-bromopyruvate (3BP) $[15,16]$. This compound has demonstrated anticancer effects both in vitro and in vivo. It directly inhibits mitochondrial bound hexokinase-II which is up-regulated in many types of cancer. A cytotoxic inhibitory effect has been documented in many types of cancer including melanoma, glioblastoma, mesothelioma, as well as pancreatic, hepatocellular and breast carcinoma $[15,16]$. 3-(3-Pyridinyl)-1-(4-pyridinyl)-2-propen-1-one] (3PO) is a novel small molecule inhibitor of PFKFB3, an isozyme which is a component of fructose-2, 6-bisphosphate (Fru-2, 6-BP), an allosteric activator of PFK1 [17]. It has been shown that $3 \mathrm{PO}$ suppresses phosphofructokinase activity, decreases glucose uptake and induces growth inhibition in several cell lines, including Ras-transformed cells and additionally in established tumors in vivo [17]. PFK158, an optimised 3PO compound, is now undergoing a clinical trial [18].

Dichloroacetate (DCA) is a pyruvate analogue which inhibits pyruvate dehydrogenase kinase (PDHK1), 
an enzyme which inhibits the mitochondrial pyruvate dehydrogenase (PDH). In this way it suppresses glycolysis and stimulates oxidative phosphorylation. It is reported to have antitumor activity both in vitro, in several types of cancer, and in vivo $[19,20]$. DCA is now currently undergoing clinical trials [21] and while promising results were obtained in 3 of 5 glioblastoma patients treated with DCA alongside temozolomide and radiotherapy [22], combination therapy trials with platinum have so far failed to show activity against non-small cell lung cancer [23]. Furthermore, the drug is not without toxicity and at high concentrations produces peripheral neuropathy [22]. Oxamic acid is an established pyruvate analogue and a competitive lactate dehydrogenase (LDH) inhibitor. Some promising anti-proliferative effects have been documented in vitro using cervical adenocarcinoma and hepatocellular carcinoma cell lines [24, 25]. In 2011 Granchi et al. published the identification of several novel N-hydroxyindole-based (NHI) LDH Inhibitors [26]. NHI-1 (aka compound $1 \mathrm{j}$ ) is a competitive isoform selective $\mathrm{LDH}$ A inhibitor [26]. It has been shown to diminish lactate production and inhibit cell proliferation in a variety of cancer cell lines [26, 27].

This study examined the effects of these inhibitors on breast and ovarian cancer cell lines by using cell proliferation, glucose and lactate assays, to assess impact on aerobic glycolysis. While there are reports of these agents showing activity against various cancer cell line models, we are not aware of any detailed comparative studies of multiple inhibitors against panels of either breast or ovarian cancer cell line models. We sought to understand why certain cell lines were more sensitive to inhibitors of these pathways.

Metformin is a biguanide widely prescribed for the treatment of type 2 diabetes mellitus. An increasing number of epidemiologic studies have associated metformin with a decreased risk of several types of cancer and improved clinical outcome in diabetic cancer patients [28]. Metformin inhibits the mitochondrial respiratory chain complex I and its anticancer effect is mainly attributed to the activation of the AMP-activated protein kinase (AMPK) resulting in decreased hepatic gluconeogenesis [28-30]. Here we hypothesized that since metformin decreases ATP production, inhibiting mitochondrial oxidative phosphorylation, a combined inhibition of the glycolytic pathway could possibly result in a complete depletion of cellular ATP and lead to increased cell death.

An additional objective of this study was to evaluate the effect of these inhibitors under varying oxygenation levels. Previous reports have revealed considerable intratumoral heterogeneity in oxygenation status, as well as increased variability among individual solid tumors [31]. For breast cancers, Vaupel et al. reported marked variability in oxygen levels (from $13 \%-0 \%$ oxygen) even when comparing tumors of the same stage, grade and histology. Furthermore, they demonstrated great heterogeneity in the oxygenation of individual tumors with hypoxic and anoxic areas distributed within the same tumor tissue [31]. Hypoxia is a well substantiated common feature of the tumor microenvironment that contributes to resistance to radiotherapy, chemotherapy and tumor relapse. The transcription factor HIF-1 (Hypoxia Inducible Factor 1) is induced by hypoxia and regulates expression of proteins that enable cells to survive hypoxia [32]. Many of the glycolytic enzymes, including all the targets selected here (GLUT1, Hexokinase II, PFKFB3, PDHK1 and LDHA), are known to be HIF1-inducible [32]. Previous studies using these inhibitors have demonstrated both reduced and increased potency in hypoxic conditions dependent on the inhibitor and cancer model, hence we were interested to ascertain their effects in breast and ovarian cancer cell line models. To date, most experimental studies have been carried out under normoxic conditions. This study investigated the sensitivity of breast cancer cells to glycolytic inhibitors at a range of oxygen levels $\left(21 \%-7 \%-2 \%-0.5 \% \mathrm{O}_{2}\right)$, the latter three representing more closely the microenvironment of clinical cancers.

\section{RESULTS}

\section{Targeted inhibition of the glycolysis pathway in breast and ovarian cancer cell lines}

The effect of inhibitors targeted against upstream components of the glycolysis pathway (GLUT1, hexokinase II, PFKFB3) and the downstream component LDH-A were compared on cell proliferation. These were also compared with an inhibitor (DCA) of PDHK1 which promotes conversion of pyruvate to acetyl-CoA. Proliferation was assessed by use of a sulphorhodamine B (SRB) assay and growth was assayed after a 5-day treatment period. Concentration response curves for the breast and ovarian cancer cell lines (Supplementary Table 1) are illustrated in Figures 2 and 3 respectively and $\mathrm{IC}_{50}$ values are recorded in Table 1.

Four breast cancer cell lines (MCF-7, MDAMB-231, HBL100 and BT549) were first investigated (Figure 2). Four GLUT1 inhibitors, Phloretin, Quercetin, STF31 and WZB117, were compared. The flavonoids Phloretin and Quercetin had similar effects on the growth of the cell lines. For Phloretin, the $\mathrm{IC}_{50}$ values ranged between 36-135 $\mu \mathrm{M}$ while $\mathrm{IC}_{50}$ values ranged between 44-106 $\mu \mathrm{M}$ for Quercetin. STF31 produced a much larger differential effect between the cell lines. MCF7 and HBL100 cells were very sensitive while BT549 cells showed resistance to the compound. The $\mathrm{IC}_{50}$ values varied markedly and ranged between $0.2-18 \mu \mathrm{M}$. In contrast, WZB117 had a very similar effect on all four cell lines with $\mathrm{IC}_{50}$ values ranging between 5.2-6.6 $\mu \mathrm{M}$. 3BP which targets hexokinase II had $\mathrm{IC}_{50}$ values that ranged between 10-84 $\mu \mathrm{M}$; MCF-7, HBL100 and BT549 cells had a similar response, while MDA-MB-231 cells were 


\section{Breast cancer cell lines}
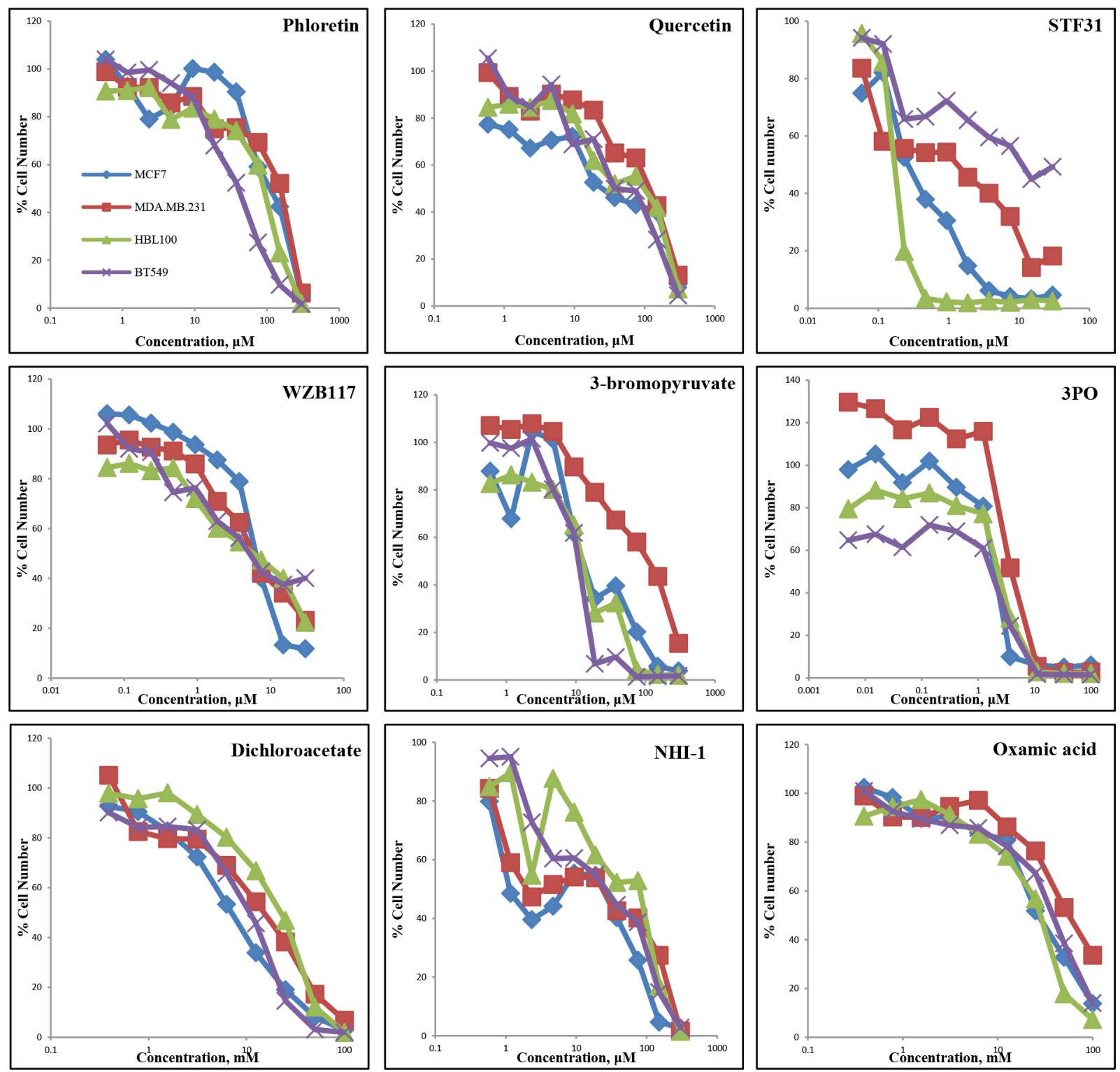

Figure 2: Concentration response curves of four breast cancer cell lines (MCF-7, MDA-MB-231, HBL100, BT549) treated with nine glycolytic inhibitors. Breast cancer cells were treated with Phloretin concentrations between 0.6-300 $\mu \mathrm{M}$,

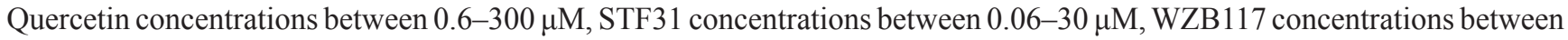
$0.06-30 \mu \mathrm{M}, 3 \mathrm{BP}$ concentrations between $0.6-300 \mu \mathrm{M}, 3 \mathrm{PO}$ concentrations between $0.005-100 \mu \mathrm{M}$, DCA concentrations between 0.4-100 mM, Oxamic acid concentrations between $0.2-100 \mathrm{mM}$ and NHI-1 concentrations between $0.6-300 \mu \mathrm{M}$. An SRB assay was performed on day 5. Results shown here are in replicates of 6 . Constant $0.3 \%$ DMSO concentration was used across the whole curve for Phloretin, Quercetin, STF31 and NH-1. Constant $0.3 \%$ ethanol concentration was used across the whole curve for WZB117.

more resistant. All cell lines responded in a similar way to $3 \mathrm{PO}$ which targets PFKFB3 having $\mathrm{IC}_{50}$ values between 2.1-3.8 $\mu \mathrm{M}$. For DCA the concentrations needed were higher compared to the previous inhibitors and were in the millimolar concentration range. MCF-7 proved the most sensitive breast cancer cell line $\left(\mathrm{IC}_{50} 6.8 \mathrm{mM}\right)$, while HBL100 $\left(\mathrm{IC}_{50} 18.9 \mathrm{mM}\right)$ was least sensitive. Finally, for NHI-1 and Oxamic acid which target LDH-A, the $\mathrm{IC}_{50}$ values ranged between $27-58 \mathrm{mM}$ for Oxamic acid and between $8-53 \mu \mathrm{M}$ for NHI-1. The MDA-MB-231 cell line was found more resistant to several of the inhibitors.

For the 4 ovarian cancer cell lines, similar datasets were obtained (Figure 3). Phloretin inhibited cell proliferation with $\mathrm{IC}_{50}$ values ranging between 51-197 $\mu \mathrm{M}$ and Quercetin with values between 21-240 $\mu \mathrm{M}$. STF31 and WZB117 produced increased differential effects 


\section{Ovarian cancer cell lines}
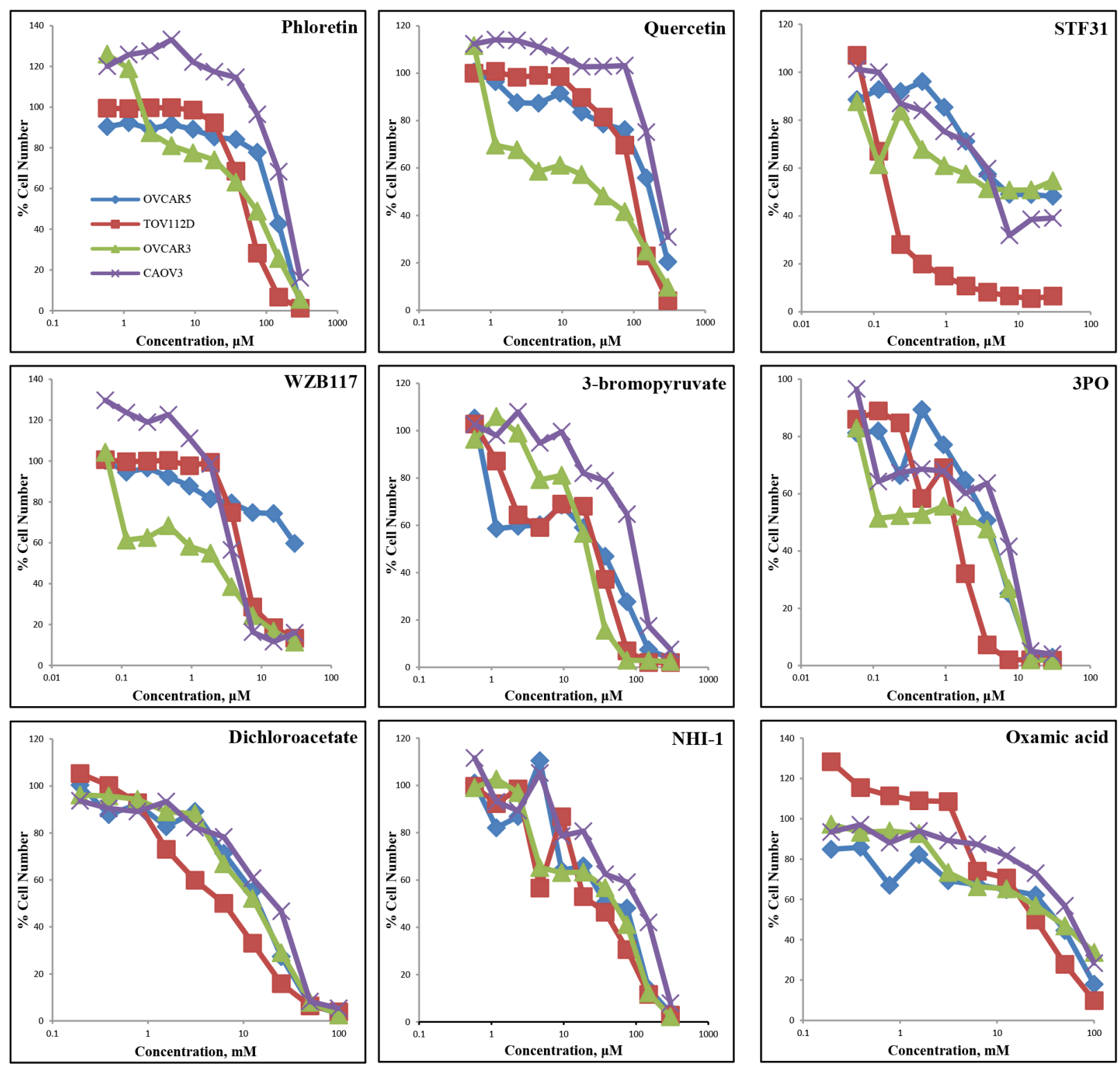

Figure 3: Concentration response curves of four ovarian cancer cell lines (OVCAR5, TOV112D, OVCAR3, CAOV3) treated with nine glycolytic inhibitors. Ovarian cancer cells were treated with Phloretin concentrations between $0.6-300 \mu \mathrm{M}$, Quercetin concentrations between 0.6-300 $\mu \mathrm{M}$, STF31 concentrations between 0.06-30 $\mu \mathrm{M}$, WZB117 concentrations between 0.06-30 $\mu \mathrm{M}$,

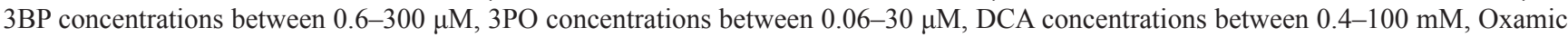
acid concentrations between $0.2-100 \mathrm{mM}$ and NHI-1 concentrations between 0.6-300 $\mu \mathrm{M}$. An SRB assay was performed on day 5. Results shown here are in replicates of 6 . Constant $0.3 \%$ DMSO concentration was used across the whole curve for Phloretin, Quercetin, STF31 and NH-1. Constant $0.3 \%$ ethanol concentration was used across the whole curve for WZB117

between the cell lines. The $\mathrm{IC}_{50}$ values ranged between 0.2 to greater than $30 \mu \mathrm{M}$ for STF31 and between 1.4 to greater than $30 \mu \mathrm{M}$ for WZB117. OVCAR3 cells demonstrated resistance to STF31 and OVCAR5 cells were resistant to WZB117. For 3BP, the $\mathrm{IC}_{50}$ values ranged between 16-84 $\mu \mathrm{M}$ with the CAOV3 cell line demonstrating most resistance to this compound. Regarding 3PO, the TOV112D cell line was the most sensitive with $\mathrm{IC}_{50}$ value almost $1.2 \mu \mathrm{M}$ while CAOV3 was least sensitive, with an $\mathrm{IC}_{50} 5$ times higher. DCA and Oxamic acid again required much greater (millimolar) concentrations compared to the other compounds. In both cases, TOV112D cell line showed the lowest $\mathrm{IC}_{50}$ values $(5.5 \mathrm{mM}$ for DCA and $24 \mathrm{mM}$ for Oxamic acid) while CAOV3 had the highest (20 mM for DCA and $59 \mathrm{mM}$ for Oxamic acid). Finally, for NHI-1 the $\mathrm{IC}_{50}$ values ranged between 28-91 $\mu \mathrm{M}$. 
Table 1: Summary of the $\mathrm{IC}_{50}$ concentrations obtained from four breast and four ovarian cancer cell lines when treated with the indicated glycolytic inhibitors for 5 days

\begin{tabular}{|l|c|c|c|c|c|c|c|c|}
\hline & MCF-7 & MDA-MB-231 & HBL100 & BT549 & \multicolumn{1}{c}{ OVCAR5 } & TOV112D & OVCAR3 & CAOV3 \\
\hline Phloretin $(\mu \mathrm{M})$ & 122 & 135 & 69 & 36 & 119 & 51 & 54 & 197 \\
\hline Quercetin $(\mu \mathrm{M})$ & 44 & 105 & 76 & 44 & 154 & 94 & 21 & 240 \\
\hline STF31 $(\mu \mathrm{M})$ & 0.31 & 0.81 & 0.17 & 18 & 7.4 & 0.15 & $>30$ & 4.9 \\
\hline WZB117 $(\mu \mathrm{M})$ & 6.4 & 6.3 & 5.2 & 6.6 & $>30$ & 5.9 & 1.4 & 4.3 \\
\hline Bromopyruvate $(\mu \mathrm{M})$ & 18 & 84 & 15 & 10 & 20 & 16 & 20 & 84 \\
\hline 3PO $(\mu \mathrm{M})$ & 2.1 & 3.8 & 2.7 & 2.3 & 3.9 & 1.2 & 2.8 & 5.8 \\
\hline Dichloroacetate $(\mathrm{mM})$ & 6.8 & 13 & 19 & 9.1 & 14 & 5.5 & 13 & 20 \\
\hline Oxamic acid $(\mathrm{mM})$ & 28 & 58 & 27 & 39 & 38 & 24 & 34 & 59 \\
\hline NHI-1 $(\mu \mathrm{M})$ & 8 & 20 & 53 & 22 & 45 & 28 & 35 & 91 \\
\hline
\end{tabular}

\section{Glucose uptake and lactate production are inhibited by all of the studied inhibitors}

The effects of the above inhibitors were next examined on glucose uptake and lactate production in HBL100 and
MCF-7 cells (Figure 4). Glucose concentrations remaining in the media and extracellular lactate production into the medium after a $24 \mathrm{~h}$ treatment with the indicated compound are shown. The range of concentrations used for each compound was based on the corresponding $\mathrm{IC}_{50}$ values, derived from the SRB
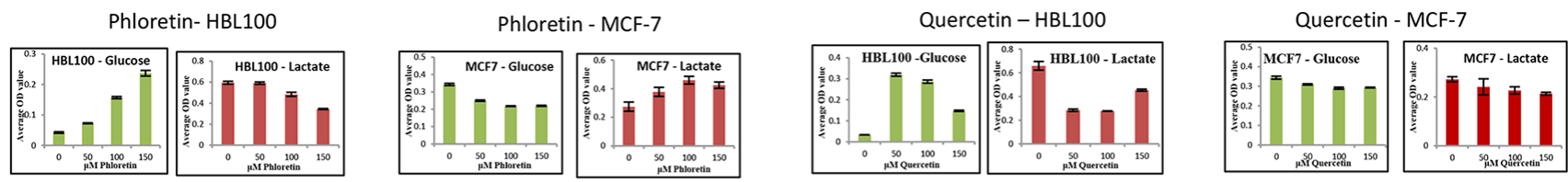

STF31 - HBL100

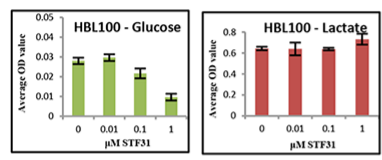

STF31 - MCF-7

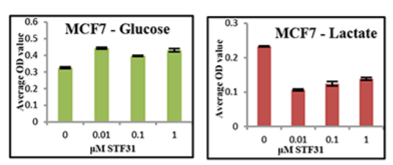

WZB117 - HBL100

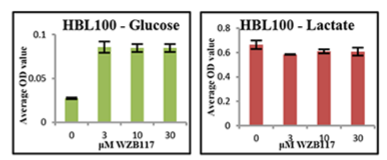

WZB117 - MCF-7

3 BP - HBL100

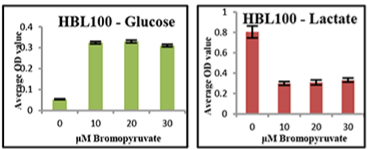

$3 \mathrm{BP}-\mathrm{MCF}-7$
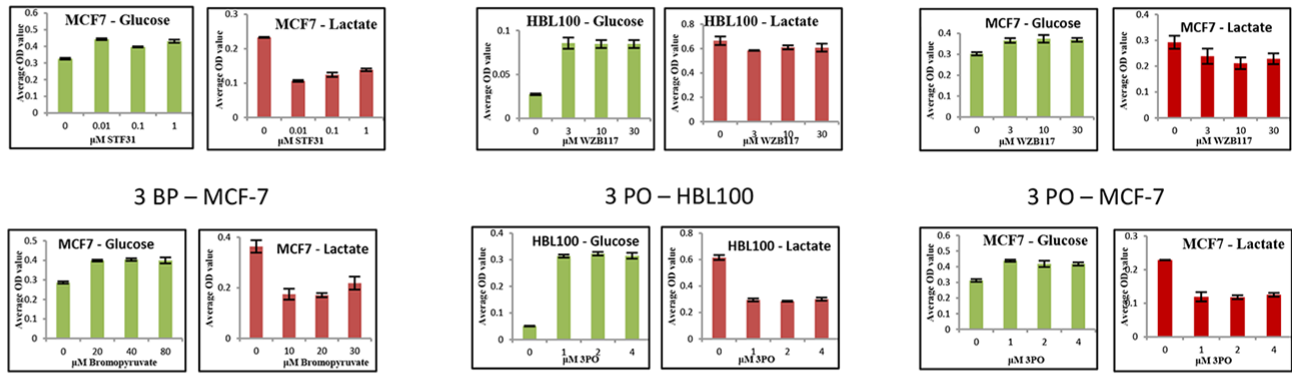

$3 \mathrm{PO}-\mathrm{MCF}-7$

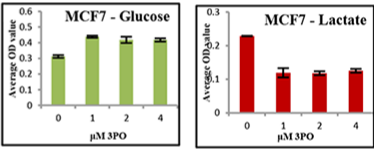

DCA - HBL100

DCA - MCF-7
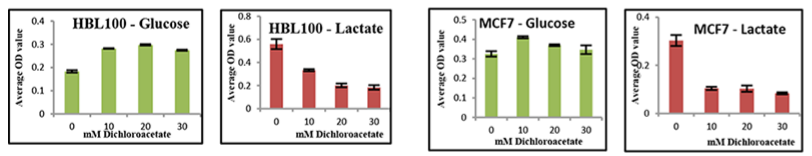

Oxamic acid - HBL100

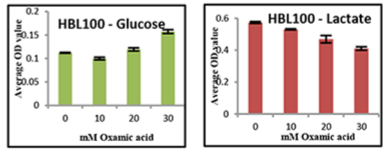

Oxamic acid - MCF-7

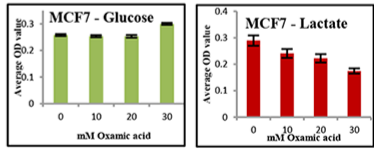

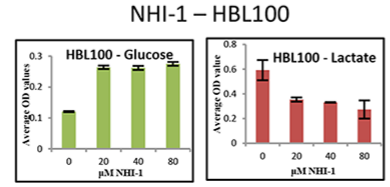

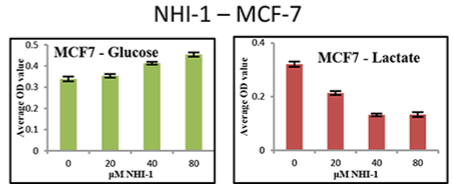

Figure 4: Extracellular glucose remaining in the media and extracellular lactate secreted against increasing concentration of the nine glycolytic inhibitors after a $24 \mathrm{~h}$ treatment of MCF-7 or HBL100 cells. Results are reported as the mean of three repeats and error bars represent standard deviations. 
assay, for each specific cell line. Both sets of measurements were conducted on the same day from the same sample.

All the inhibitors tested proved effective in blocking glycolysis in at least one of the two cell lines tested (Figure 4). Increasing concentrations of Phloretin caused an increase in the glucose remaining in the media while lactate production decreased following the same pattern. Regarding the other three glucose transport inhibitors Quercetin, STF31 and WZB117, even the lowest concentration used produced a maximal effect causing accumulation of glucose and depletion of lactate in the culture media. 3BP, 3PO and DCA were also effective in inhibiting glycolysis. Low concentrations of each compound caused a large increase in the glucose accumulating in the media and a corresponding decline in the secreted lactate. The inhibition of glycolysis hit a plateau with treatment of $10 \mu \mathrm{M} 3 \mathrm{BP}, 10 \mu \mathrm{M} 3 \mathrm{PO}$ or $10 \mathrm{mM}$ DCA and no apparent additional effect was detected with increasing concentrations. The lactate dehydrogenase inhibitors likewise suppressed glycolysis. Following treatment with NHI-1 and Oxamic acid, cells demonstrated a modest increase in glucose and a more profound depletion of lactate in their culture media.

\section{Glycolytic inhibitors induced apoptosis}

To investigate whether the growth inhibitory effect of these compounds was associated with induction of apoptotic cell death, flow cytometric analysis was performed. MCF-7 cells were treated with 9 glycolytic inhibitors for $48 \mathrm{~h}$, stained with FITC-conjugated Annexin V and PI and analysed using flow cytometry. Cells were separated into four different groups, the lower left quadrant represents intact viable cells (Annexin negative and PI negative), the upper left quadrant represents early apoptotic cells (Annexin positive and PI negative), the upper right quadrant represents late apoptotic cells (Annexin positive and PI positive) and the lower right quadrant represents necrotic cells (Annexin negative and PI positive). Cells stained with Annexin-FITC were collectively considered as apoptotic cells (upper region). As shown in Figure 5A there

A.
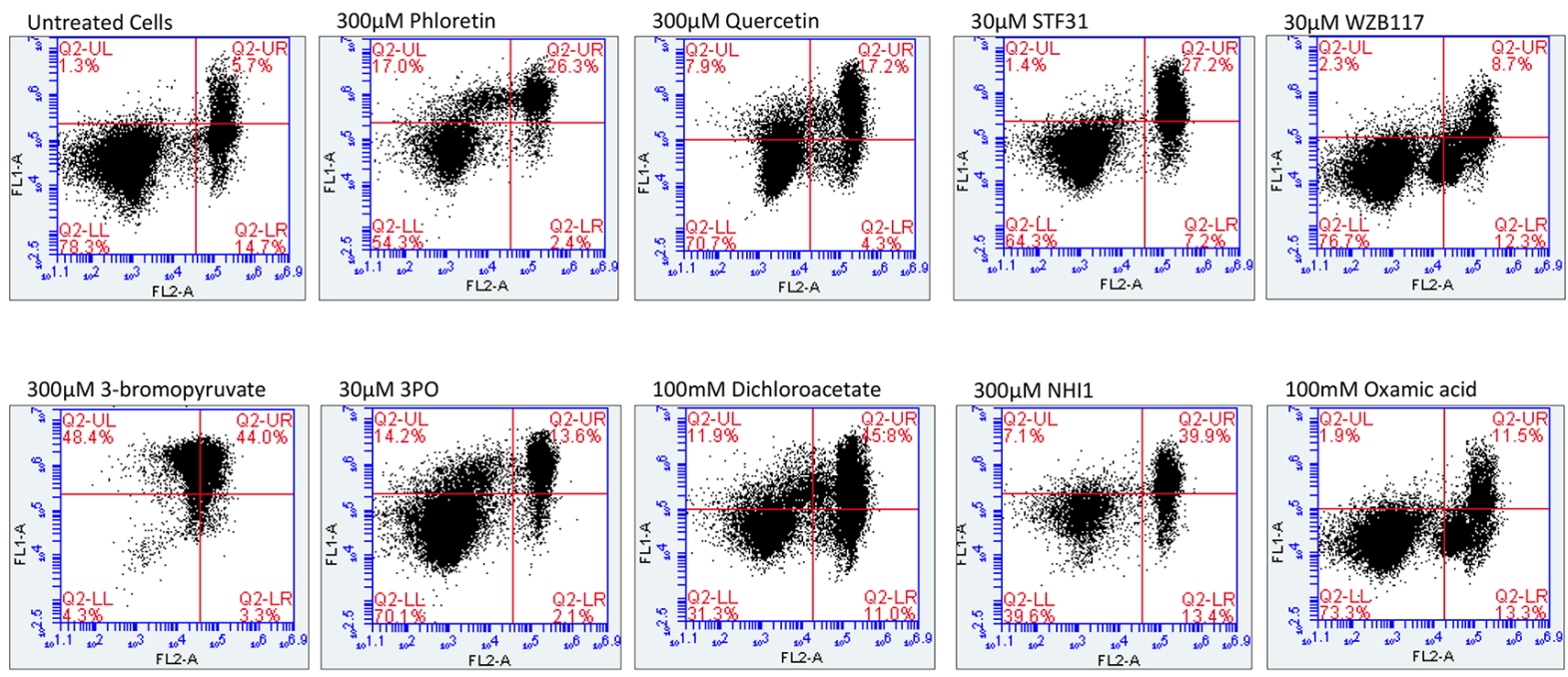

B.

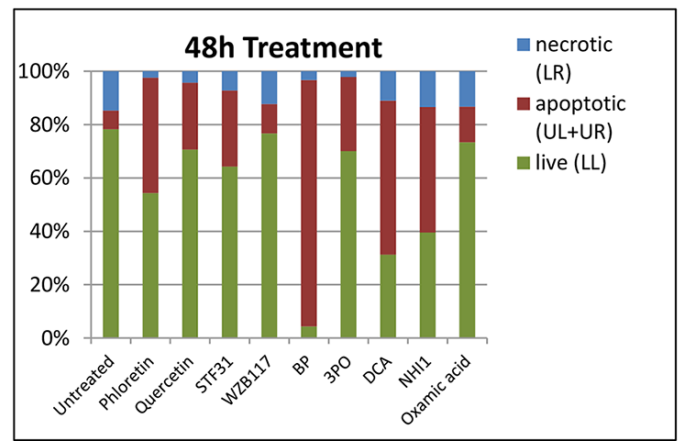

Figure 5: A. Two- dimensional scatter plots of Annexin V (FL1) vs PI (FL2) generated from flow cytometry analysis of MCF-7 cells when treated with 9 glycolytic inhibitors for 48 h. After treatment cells were harvested, washed with cold PBS and resuspended in 1X Binding Buffer. $5 \mu 1$ of FITC Annexin and $5 \mu 1$ of PI were added to the suspension and cells were incubated for $15 \mathrm{~min}$ in the dark prior to analysis with the BD Accuri C6. The numbers in the quadrants of each plot indicate the percentage of cells in this region. Cells in LL represent intact viable cells (Annexin negative and PI negative), in UL represent early apoptotic cells (Annexin positive and PI negative), in UR represent late apoptotic cells (Annexin positive and PI positive) and in LL represent necrotic cells (Annexin negative and PI positive). B. Percentage of apoptotic, necrotic and live cells after a $48 \mathrm{~h}$ treatment with $300 \mu \mathrm{M}$ Phloretin, $300 \mu \mathrm{M}$ Quercetin, $30 \mu \mathrm{M}$ STF31, $30 \mu \mathrm{M}$ WZB117, $300 \mu \mathrm{M}$ 3BP, $30 \mu \mathrm{m}$ 3PO, $100 \mathrm{mM}$ DCA, $300 \mu \mathrm{M}$ NHI-1 and 100mM Oxamic acid compared to untreated cells. 
is an induction of both early and late phases of apoptosis after treatment with the glycolytic inhibitors compared to untreated cells. Untreated cells showed 7\% apoptosis (Annexin positive) whereas for cells treated with $300 \mu \mathrm{M}$ Phloretin the percentage of apoptotic cells increased to $43 \%$, with $300 \mu \mathrm{M}$ Quercetin to $25 \%$, with $30 \mu \mathrm{M}$ STF31 to $29 \%$, with $30 \mu \mathrm{M}$ WZB117 to $11 \%$, with $300 \mu \mathrm{M} 3 \mathrm{BP}$ to $92 \%$, with $30 \mu \mathrm{M} 3 \mathrm{PO}$ to $28 \%$, with $100 \mathrm{mM}$ DCA to $58 \%$, with $300 \mu \mathrm{M}$ NHI- 1 to $47 \%$ and with $100 \mathrm{mM}$ Oxamic acid to $13 \%$ (Figure 5B).

\section{Correlation analysis of $\mathrm{IC}_{50}$ concentrations and cell proliferation rate}

The association of $\mathrm{IC}_{50}$ values against the panel of 8 cell lines was assessed for each pair of drugs indicating that sensitivity to 7 of these inhibitors correlated with each other (Supplementary Table 2). The correlation heatmap in Figure 6A illustrated that 7 inhibitors (Phloretin, Quercetin, 3BP, 3PO, DCA, NHI-1 and Oxamic acid) had $\mathrm{IC}_{50}$ concentrations that gave high Pearson $\mathrm{R}$ correlation values when compared to each other. This is consistent with these agents sharing a common mechanism of action targeting the same pathway. STF31 and WZB117 did not significantly correlate with any of the other agents. The expression levels of GLUT1, hexokinase II, PFKFB3, PDHK1 and LDHA were examined in the cell line panel (Supplementary Figure 1). No significant correlation between the expression of the targets in the eight cell lines and their sensitivity to the inhibitors was detected

A.
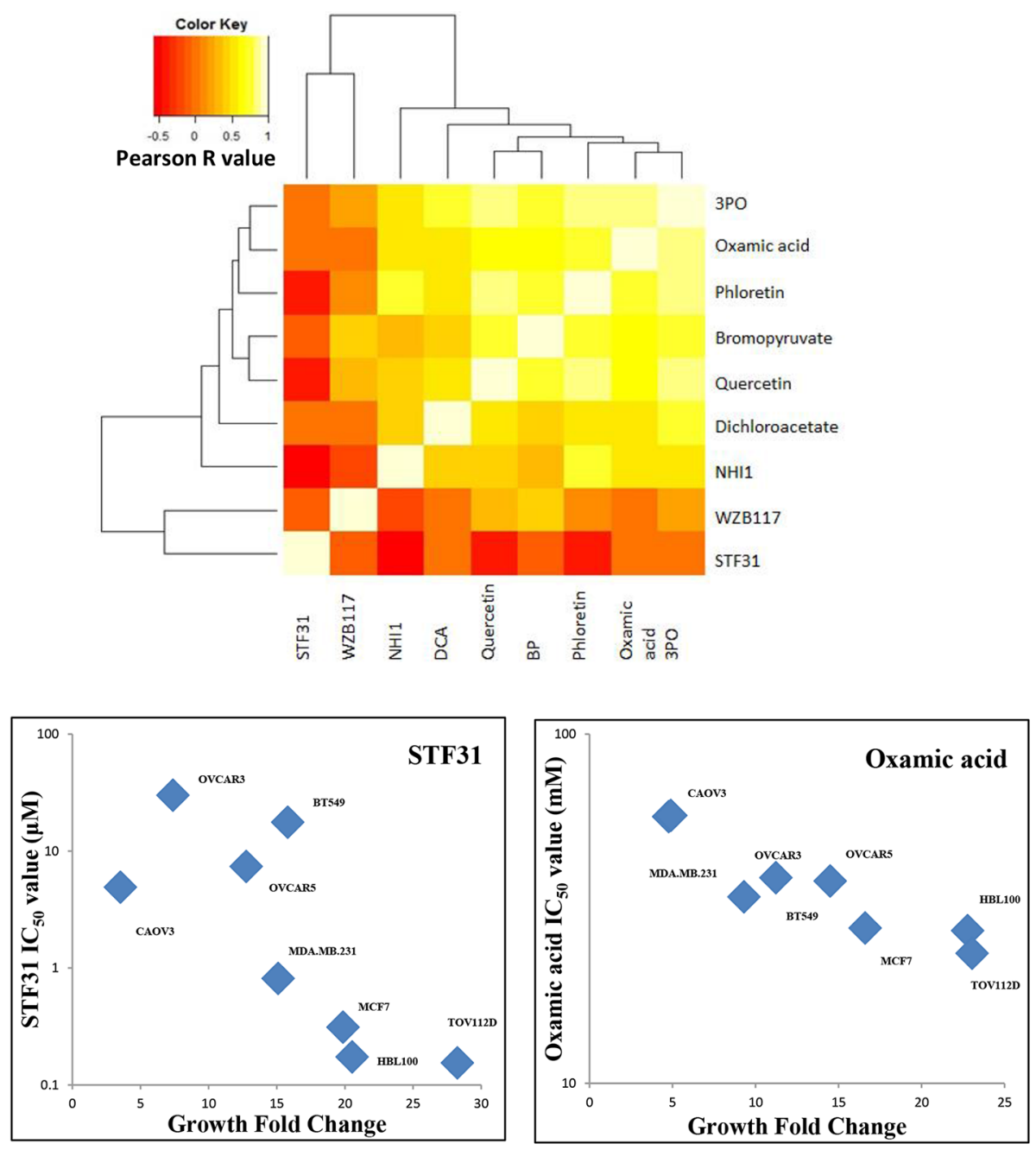

Figure 6: A. Correlation heat-map demonstrating that seven glycolytic inhibitors had $\mathrm{IC}_{50}$ concentrations that correlated with each other in the panel of cell lines. This is consistent with a shared mechanism of action. Dark orange colours indicate negative Pearson R correlation values while bright white colours indicate positive Pearson R correlation values. B. STF31 and Oxamic acid $\mathrm{IC}_{50}$ values of the panel of four breast and four ovarian cancer cell lines plotted against the growth fold change of the respective cell line. Non-parametric Spearman correlation $\mathrm{r}=-0.7619$ with two-tailed $P$ value 0.0368 for STF31; considered significant. Non-parametric Spearman correlation $\mathrm{r}=-0.9048$ with two-tailed $P$ value 0.0046 for Oxamic acid; considered very significant. 
(data not shown). Sensitivity to STF31 and Oxamic acid was found to correlate significantly with the proliferation rate of the cell lines, giving $p$ values of 0.0368 and 0.0046 respectively. The fastest growing cell lines were more sensitive to these compounds while the slowest growing cell lines presented greater resistance (Figure 6B).

\section{Combination of metformin and glycolytic inhibitors synergistically inhibited cancer cell growth of a triple negative breast cancer cell line}

The interaction between glycolytic inhibitors and the antidiabetic drug metformin was examined. A range of different concentrations of two glycolytic inhibitors, STF31 and Oxamic acid, was used in combination with a constant fixed concentration of metformin and incubation lasted for $72 \mathrm{~h}$. Metformin enhanced the potency of both STF31 and Oxamic acid to inhibit cancer cell proliferation compared to the effect of these drugs individually (Figure 7A). To evaluate the efficacy of the combinations, data were analysed using the Calcusyn Software and Combination Index (CI) values were generated (Tables 2a, 2b). Examples of synergistic combinations are depicted in Figure 7B. For example, $1.9 \mu \mathrm{M}$ of STF31 alone reduced the percentage of cell number to $78 \%$ and $3 \mathrm{mM}$ of metformin to $87 \%$ while the combination of both drugs reduced the cell number to $37 \%$ compared to untreated cells. For this combination a CI value equal to 0.182 is generated which is characterised as

A.

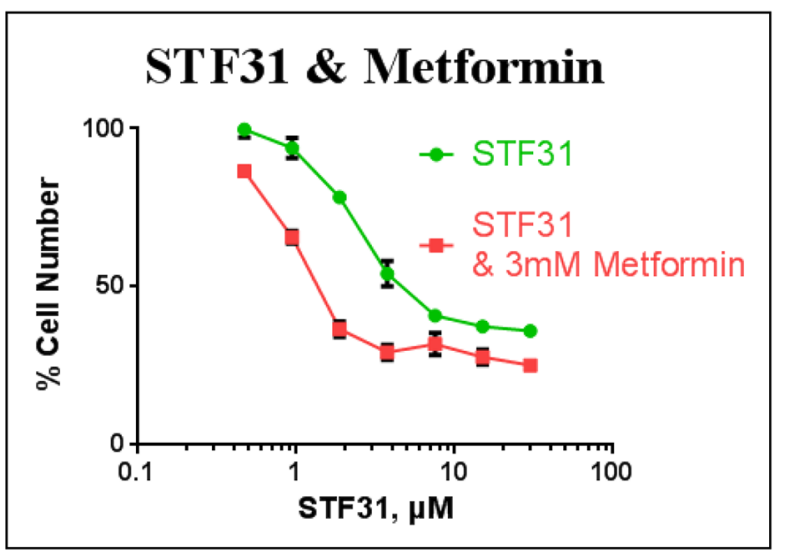

\section{Oxamic acid \& Metformin}

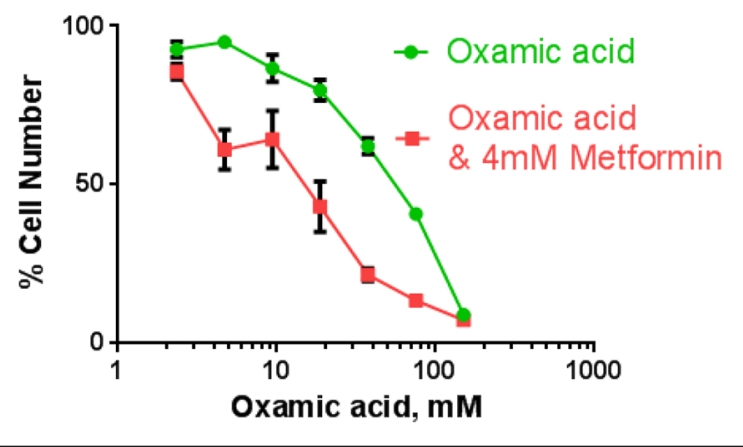

B.
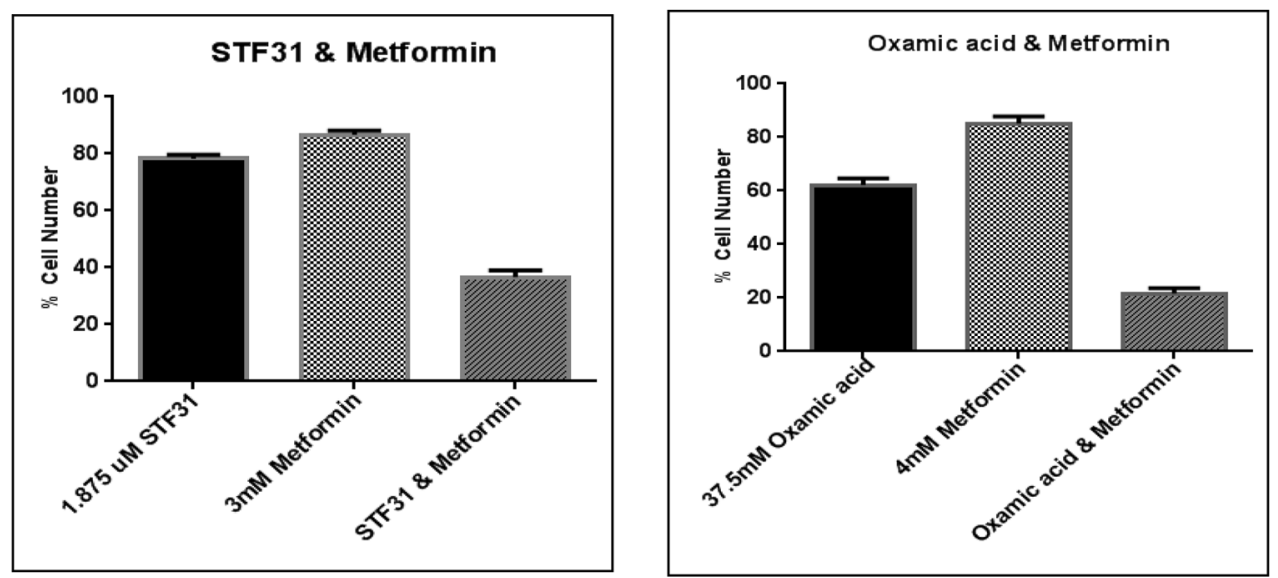

Figure 7: A. Concentration response curves of drug interaction studies. MDA-MB-231 cells were treated with STF31 concentrations between $0.5-30 \mu \mathrm{M}$ and Oxamic acid concentrations between $2.3-150 \mathrm{mM}$ alone or in combination with a constant concentration of $3 \mathrm{mM}$ or $4 \mathrm{mM}$ metformin respectively. An SRB assay was performed on day 3. Error bars shown here represent SD $(n=6)$. B. Effect of $2 \mu \mathrm{M} \mathrm{STF} 31$ alone or in combination with $3 \mathrm{mM}$ metformin and of $38 \mathrm{mM}$ Oxamic acid alone or in combination with $4 \mathrm{mM}$ metformin on cell viability. Both combinations are characterised synergistic based on their CI values generated using the Calcusyn Software. Error bars shown here represent SD $(n=6)$. 


\section{Table 2: Summary of drug interaction studies}

a.

\begin{tabular}{|l|c|c|c|}
\hline STF31 $(\boldsymbol{\mu M})$ & Metformin $(\boldsymbol{\mu M})$ & Fa & CI \\
\hline 0.46875 & 3000 & 0.134506 & $\mathbf{1 . 1 8 3}$ \\
\hline 0.9375 & 3000 & 0.343076 & $\mathbf{0 . 3 6}$ \\
\hline 1.875 & 3000 & 0.63395 & $\mathbf{0 . 1 8 2}$ \\
\hline 3.75 & 3000 & 0.706688 & $\mathbf{0 . 2 5 1}$ \\
\hline 7.5 & 3000 & 0.68129 & $\mathbf{0 . 5 2 2}$ \\
\hline 15 & 3000 & 0.721799 & $\mathbf{0 . 8 8 2}$ \\
\hline 30 & 3000 & 0.747518 & $\mathbf{1 . 5 8 5}$ \\
\hline
\end{tabular}

b.

\begin{tabular}{|l|c|c|c|}
\hline Oxamic acid $(\mathbf{m M})$ & Metformin $(\mathbf{m M})$ & Fa & CI \\
\hline 2.34375 & 4 & 0.144005 & $\mathbf{1 . 6 8 3}$ \\
\hline 4.6875 & 4 & 0.389971 & $\mathbf{0 . 4 6 7}$ \\
\hline 9.375 & 4 & 0.356693 & $\mathbf{0 . 7 3}$ \\
\hline 18.75 & 4 & 0.568973 & $\mathbf{0 . 4 8 3}$ \\
\hline 37.5 & 4 & 0.783404 & $\mathbf{0 . 3 3 6}$ \\
\hline 75 & 4 & 0.864651 & $\mathbf{0 . 3 8 2}$ \\
\hline 150 & 4 & 0.926606 & $\mathbf{0 . 4 1 1}$ \\
\hline
\end{tabular}

Tables show concentration range of STF31 (2a) and Oxamic acid (2b) used with a constant concentration of Metformin. FAfraction affected represents the growth inhibition for each tested combination and CI represents the combination index values generated through Calcusyn. Values lower than 0.8 indicate synergism, values between 0.8 and 1.2 indicate additivity and values higher than 1.2 indicate antagonism

strong synergy. Similarly, $37.5 \mathrm{mM}$ of Oxamic acid reduced cell number to $62 \%$ and $4 \mathrm{mM}$ of metformin to $85 \%$ while their combination reduced the cell number to $22 \%$. The CI value generated for this combination was 0.336 characterised as synergy.

\section{Growth inhibition at varying oxygen tensions}

We next sought to examine the effect of the oxygen level on sensitivity to these glycolytic inhibitors. For this purpose two breast cancer cell lines were selected, the ER positive, luminal A MCF-7 and the basal B, triple negative MDA-MB-231 lines. The breast cancer cells were adapted to the different oxygen conditions, before being treated with eight of the glycolytic inhibitors. The SRB assay was performed after a five day treatment. In Figure 8 is depicted the percentage of cell number for the two cell lines against increasing concentration of each of the eight compounds under four different oxygen conditions $21 \% \mathrm{O}_{2}, 7 \% \mathrm{O}_{2}, 2 \% \mathrm{O}_{2}, 0.5 \% \mathrm{O}_{2}$. Table 3 presents the corresponding $\mathrm{IC}_{50}$ values.

Both cell lines were sensitive to all the inhibitors in hypoxic conditions. The most striking observation was the increase presented in the $\mathrm{IC}_{50}$ values between $21 \% \mathrm{O}_{2}$ and $7 \% \mathrm{O}_{2}$. Both cell lines when treated with the eight inhibitors under $7 \% \mathrm{O}_{2}$ followed the same pattern and their $\mathrm{IC}_{50}$ values were increased from 1.5 fold (MDA-MB-231 cells treated with STF31 - Figure 8b) up to 9 fold (MDAMB-231 cells treated with Oxamic acid - Figure 8g) with an average of 4 fold. (Table 3 )

The response of the breast cancer cell lines at the lower oxygen levels $\left(2 \% \mathrm{O}_{2}\right.$ and $\left.0.5 \% \mathrm{O}_{2}\right)$ differed between the compounds. In some cases, cells became even more resistant to the compounds increasing further their $\mathrm{IC}_{50}$ value (e.g. MDA-MB-231 cells treated with Oxamic acid - Figure 8g), or presented a modest decrease (e.g. MDAMB-231 cells treated with DCA - Figure 8f). In the majority of the treatments, response between the three lower levels was similar. Both cell lines were more resistant to the whole panel of glycolytic inhibitors under any of the lower oxygen levels tested compared to $21 \% \mathrm{O}_{2}$ conditions (Table 3 ).

When drug $\mathrm{IC}_{50}$ was correlated with growth rate under the range of differing $\mathrm{O}_{2}$ concentrations for both cell lines, there was in general a significant inverse association between higher growth rates and lower $\mathrm{IC}_{50}$ with increasing oxygen level (Supplementary Table 3). 
a) Phloretin

b) STF31

c) WZB117
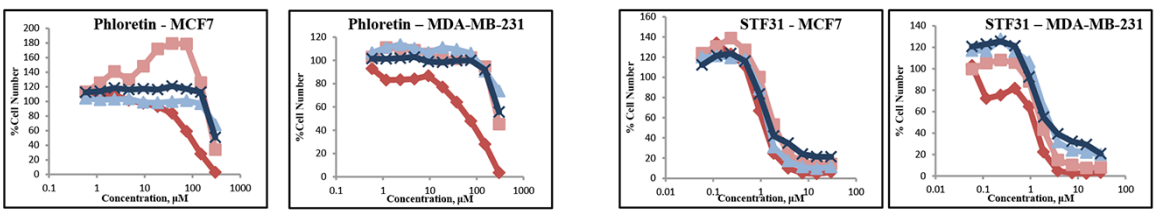

d) $3 B P$
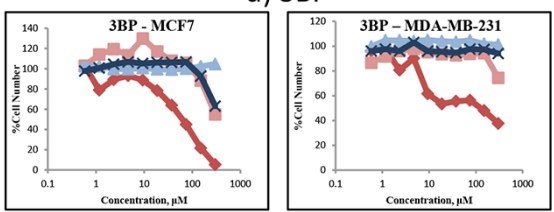

e) $3 P O$

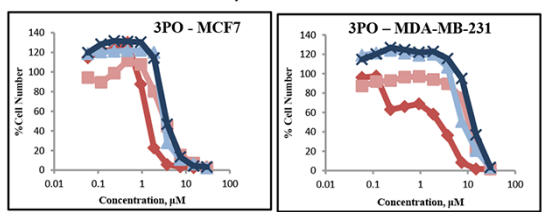

g) Oxamic acid
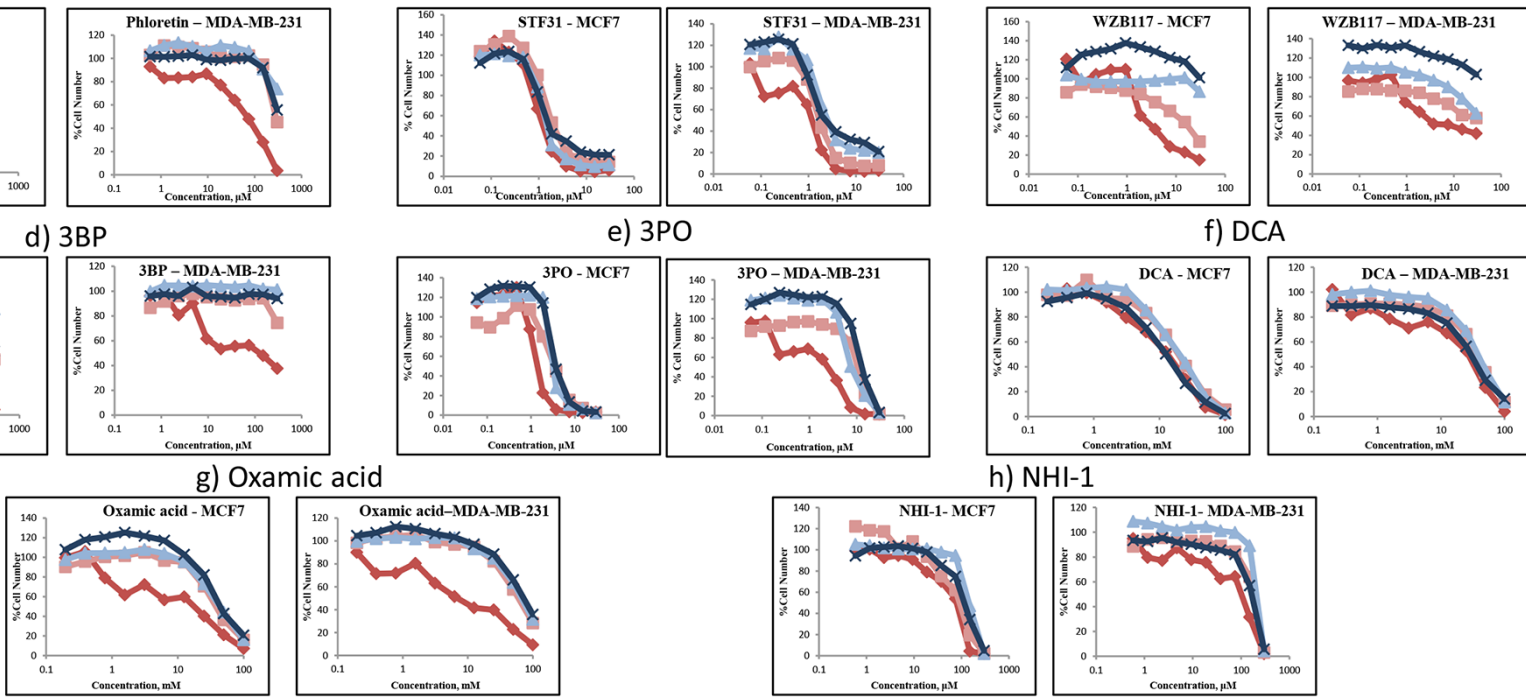

f) DCA
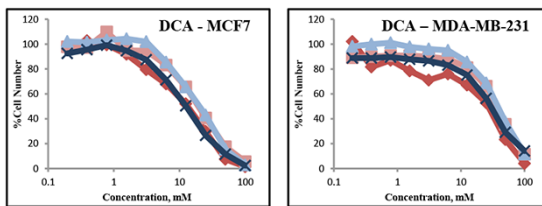

h) $\mathrm{NHI}-1$

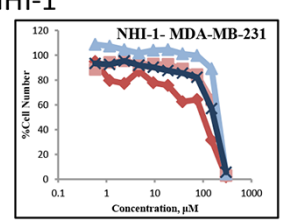

$-20 \% \mathrm{O}_{2} \longrightarrow 7 \% \mathrm{O}_{2} \longrightarrow 2 \% \mathrm{O}_{2} \longrightarrow 0.5 \% \mathrm{O}_{2}$

Figure 8: Concentration response curves of two breast cancer cell lines (MCF-7, MDA-MB-231) treated with eight glycolytic inhibitors under four different oxygen conditions $\left(21 \% \mathrm{O}_{2}, \mathbf{7 \%} \mathrm{O}_{2}, \mathbf{2 \%} \mathrm{O}_{2}, \mathbf{0 . 5 \%} \mathrm{O}_{2}\right)$. Breast cancer cells were treated with STF31 concentrations between 0.06-30 $\mu \mathrm{M}$ (Figure 8a), WZB117 concentrations between 0.06-30 $\mu \mathrm{M}$ (Figure 8b), Phloretin concentrations between 0.6-300 $\mu \mathrm{M}$ (Figure 8c), 3BP concentrations between 0.6-300 $\mu \mathrm{M}$ (Figure 8d), 3PO concentrations between 0.06$30 \mu \mathrm{M}$ (Figure 8e), DCA concentrations between 0.2-100 mM (Figure 8f), Oxamic acid concentrations between $0.2-100 \mathrm{mM}$ (Figure 8g) and NHI-1 concentrations between 0.6-300 $\mu \mathrm{M}$ (Figure 8h). An SRB assay was performed on day 5. Results shown here are in replicates of 6. Constant $0.3 \%$ DMSO concentration was used across the whole curve in Figures $8 \mathrm{a}, 8 \mathrm{c}, 8 \mathrm{e}$ and $8 \mathrm{~h}$. Constant $0.3 \%$ Ethanol concentration was used across the whole curve in Figure 8b.

Table 3: Summary of the $\mathrm{IC}_{50}$ concentrations presented from two breast cancer cell lines (MCF-7, MDA-MB-231) when treated with the indicated glycolytic inhibitors for 5 days under four different oxygen conditions $\left(21 \% \mathrm{O}_{2}, 7 \% \mathrm{O}_{2}, 2 \% \mathrm{O}_{2}\right.$, and $\left.0.5 \% \mathrm{O}_{2}\right)$

\begin{tabular}{|c|c|c|c|c|c|c|c|c|}
\hline \multirow{2}{*}{$\mathrm{IC}_{50}$} & \multicolumn{4}{|c|}{ MCF-7 } & \multicolumn{4}{|c|}{ MDA-MB-231 } \\
\hline & $21 \% \mathrm{O}_{2}$ & $7 \% \mathrm{O}_{2}$ & $2 \% \mathrm{O}_{2}$ & $0.5 \% \mathrm{O}_{2}$ & $21 \% \mathrm{O}_{2}$ & $7 \% \mathrm{O}_{2}$ & $2 \% \mathrm{O}_{2}$ & $0.5 \% \mathrm{O}_{2}$ \\
\hline STF31 $(\mu \mathrm{M})$ & 1.284 & 2.277 & 1.445 & 1.613 & 1.243 & 1.803 & 2.367 & 2.162 \\
\hline WZB117 $(\mu \mathrm{M})$ & 2.3 & 16.419 & $>30$ & $>30$ & 4.079 & $\mathrm{~N} / \mathrm{A}$ & $>30$ & N/A \\
\hline Phloretin $(\mu \mathrm{M})$ & 90.016 & 295.224 & $>300$ & $>300$ & 69.644 & 289.107 & $>300$ & $>300$ \\
\hline $\mathrm{BP}(\boldsymbol{\mu M})$ & 62.659 & $>300$ & N/A & $>300$ & 38.989 & $>300$ & N/A & $>300$ \\
\hline $3 \mathrm{PO}(\mu \mathrm{M})$ & 1.34 & 3.759 & 3.481 & 3.673 & 1.486 & 11.232 & 8.574 & 12.9 \\
\hline DCA $(\mathrm{mM})$ & 13.043 & 18.91 & 19.558 & 12.569 & 23.3 & 38.904 & 36.967 & 31.079 \\
\hline NHI1 $(\mu \mathrm{M})$ & 61.778 & 80.026 & 150.111 & 111.495 & 93.628 & 190.059 & 227.572 & 174.091 \\
\hline Oxamic acid(mM) & 10.4 & 39.368 & 47.089 & 49.478 & 6.944 & 60.431 & 66.192 & 73.993 \\
\hline
\end{tabular}

\section{Modulation of target expression levels under different $\mathrm{O}_{2}$ levels}

We speculated that decreased sensitivity to the glycolytic inhibitors in hypoxic conditions could be attributed to up-regulation of the respective target. In an attempt to understand the increased resistance to the inhibitors under lower levels of oxygen the expression of the five glycolytic targets of interest was examined in these conditions. 

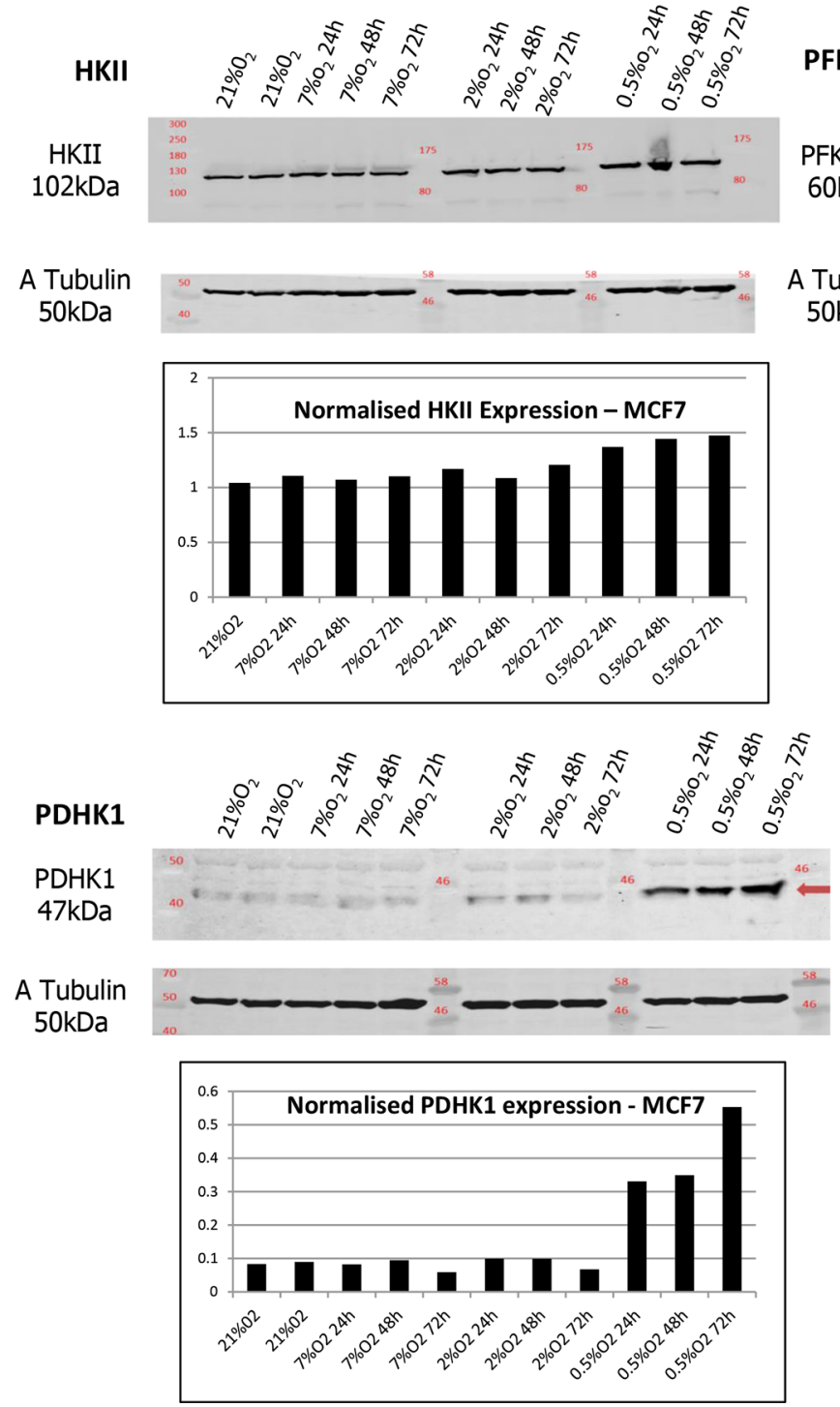
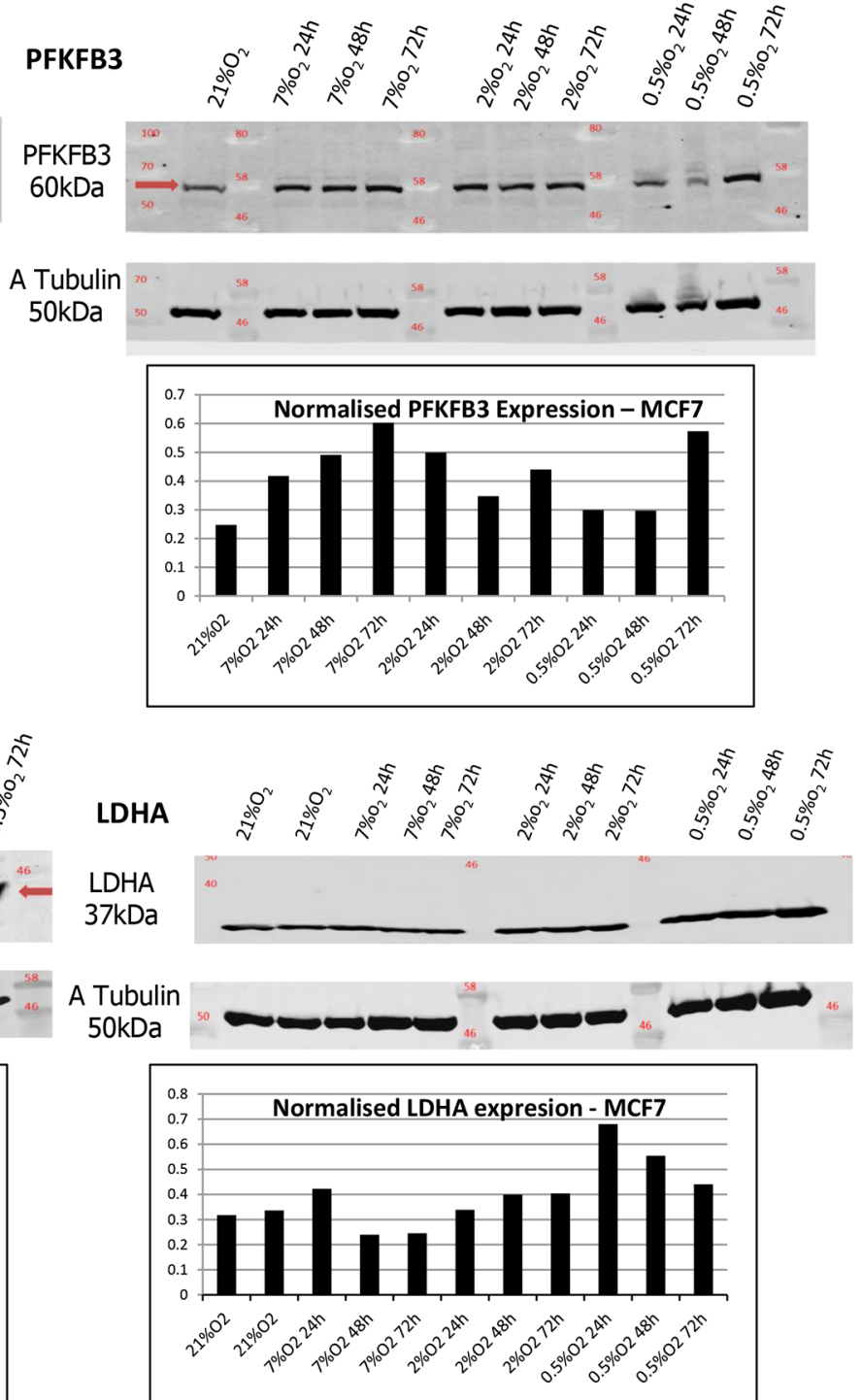

Figure 9: HKII, PFKFB3, PDHK1 and LDHA expression were examined in MCF-7 cells at different $\mathrm{O}_{2}$ levels. Lysates were taken from cells cultured in $0.5 \% \mathrm{O}_{2}, 2 \% \mathrm{O}_{2}$ and $7 \% \mathrm{O}_{2}$ for different periods of time, $24 \mathrm{~h}, 48 \mathrm{~h}$ and $72 \mathrm{~h}$. Samples are presented as follows: $21 \% \mathrm{O}_{2}, 21 \% \mathrm{O}_{2}, 7 \% \mathrm{O}_{2} 24 \mathrm{~h}, 7 \% \mathrm{O}_{2} 48 \mathrm{~h}, 7 \% \mathrm{O}_{2} 72 \mathrm{~h}, 2 \% \mathrm{O}_{2} 24 \mathrm{~h}, 2 \% \mathrm{O}_{2} 48 \mathrm{~h}, 2 \% \mathrm{O}_{2} 72 \mathrm{~h}, 0.5 \% \mathrm{O}_{2} 24 \mathrm{~h}, 0.5 \% \mathrm{O}_{2} 48 \mathrm{~h}$ and $0.5 \% \mathrm{O}_{2} 72 \mathrm{~h}$. Tubulin expression was examined in the same samples as a loading control. Densitometric analysis of HKII, PFKFB3, PDHK1 and LDHA expression was performed using the Odyssey Infrared Imaging System software (Licor).

Expression of the GLUT1 transporter as well as of the Hexokinase II, PFKFB3, PDHK1 and LDHA enzymes were examined in MCF-7 and MDA-MB-231 cells cultured in $0.5 \% \mathrm{O}_{2}, 2 \% \mathrm{O}_{2}$ as well as $7 \% \mathrm{O}_{2}$ for different periods of time, $24 \mathrm{~h}, 48 \mathrm{~h}$ and $72 \mathrm{~h}$ and compared with expression at $21 \% \mathrm{O}_{2}$ (Figure 9 - Supplementary Figures 2,3). PFKFB3 and PDHK1 were up-regulated under hypoxic conditions in both cancer cell lines, while Hexokinase II and LDHA were up-regulated only in MCF-7 cells at $0.5 \% \mathrm{O}_{2}$.

\section{DISCUSSION}

The purpose of this study was to evaluate the effects of a series of inhibitors targeted against multiple points of the glycolysis pathway in breast and ovarian cancer cell line models. All inhibitors induced apoptosis and blocked glycolysis irrespective of their target and point of action in the pathway. The majority of these compounds had $\mathrm{IC}_{50}$ concentrations that correlated significantly with each other consistent with sharing a common mechanism of action. A second objective was to examine the effect of selected glycolytic inhibitors in combination with the antidiabetic drug metformin. The third aim of the study was to investigate the impact of varying levels of $\mathrm{O}_{2}$ on inhibitor efficacy - increasing concentrations of oxygen resulted in more rapid cell growth rates and increased potency of the inhibitors.

This study provides confirmation that all 9 of these inhibitors block the glycolytic pathway. All the tested 
inhibitors caused glucose accumulation in the media of cultured cells combined with a decline in the production of lactate, the final product of glycolysis (Figure 4). It is noteworthy that even when targeting the final step of the pathway an effect on the uptake of glucose can be observed. This is attributed to the tight allosteric regulation of the key glycolytic enzymes [33]. All the tested compounds inhibited cell proliferation of both breast and ovarian cancer cells, in a concentration-dependent manner at concentrations associated with glycolytic inhibition (Figures 2, 3). Each of the inhibitors presented a different potential in attenuating cell proliferation. More recently developed compounds (STF31, WZB117, 3PO and NHI-1) proved more potent and inhibited tumor cell growth at lower concentrations. The compounds Phloretin, 3PO, DCA, NHI1 and 3BP had clear cytotoxic effects on the majority of cell lines while Quercetin, WZB117 and Oxamic acid showed cytostatic effects (judged based on the comparison of the cell number on day 0 -the day of treatment- and day 5 of treatment; data not shown). The breast and ovarian cancer cell line models studied demonstrated similar sensitivities to these agents.

GLUT1 facilitates basal glucose transport across the plasma membrane. In breast cancer, increased expression of GLUT1 has been reported to be associated with high grade tumors, basal-like subtype, high proliferative index as measured by Ki-67 and poor survival [34-37]. Similarly, an association between high GLUT1 expression and poor outcome has been observed for ovarian cancer [38] suggesting GLUT1 might be a promising target for therapeutic inhibition. The novel GLUT1 inhibitors, STF31 and WZB117 proved inhibitory at lower concentrations when compared to the flavonoids Phloretin and Quercetin. STF31 demonstrated a marked differential effect between the cell lines. It caused a potent cytotoxic effect in the HBL100 breast and TOV112D ovarian cell lines (with an $\mathrm{IC}_{50}$ as low as $0.1 \mu \mathrm{M}$ ) whereas the BT549 breast and OVCAR3 ovarian cancer cell lines were found to be highly resistant to the compound. Its activity was first reported in renal cell cancer cell line models [13] and we are unaware of antitumor data being reported in breast or ovarian cancer systems. While the breast cancer cell lines exhibited a similar response to WZB117, with almost identical $\mathrm{IC}_{50}$ values, ovarian cancer cell lines showed a significant variation in their response. OVCAR3 cells showed increased sensitivity $\left(\mathrm{IC}_{50} 1.4 \mu \mathrm{M}\right)$ while OVCAR5 cells were found resistant. In the only published report to date of WZB117, the $\mathrm{IC}_{50}$ in MCF-7 cells (approximately $10 \mu \mathrm{M})$ was similar to the value $(6.4 \mu \mathrm{M})$ observed here [14]. (Table 1).

Hexokinase II catalyses the ATP-dependent phosphorylation of glucose. Hexokinase II (HKII), the mitochondrial-bound isozyme, is associated with poor outcome in both breast [39] and ovarian cancers [40]. 3BP proved a potent compound causing a concentrationdependent reduction in the number of viable cancer cells. Breast and ovarian cancer cells presented similar sensitivity. The anti-glycolytic effect of 3BP has previously been demonstrated by decreased FDG uptake in a rat breast cancer model [41]. 3BP has also been shown to have possible value in targeting ovarian cancer tumor initiating cells [42].

PFKFB3 catalyses the ATP-dependent phosphorylation of fructose-6-phosphate and produces Fru-2, 6-BP an allosteric activator of PFK1. It is more highly expressed in breast and ovarian cancers relative to normal tissue [42]. 3PO, a PFKFB3 inhibitor, proved a potent inhibitor in these cell lines. Breast cancer cells lines responded in a similar way while the ovarian cancer cell lines exhibited greater variation in their response. 3PO has already demonstrated promising activity in an MDAMB-231 breast cancer xenograft model and since these other breast cancer cell lines tested here have increased sensitivity, while the ovarian cancer cell lines have similar sensitivities to the MDA-MB-231 cell line, this would suggest that in vivo activity might be obtained in further models [17].

PDHK1 phosphorylates and inactivates PDH and in this way prevents pyruvate from entering the mitochondrial TCA cycle. DCA effectively attenuated cell proliferation in millimolar concentrations in these cell lines and $\mathrm{IC}_{50}$ values varied between 5 and $20 \mathrm{mM}$ (Table 1). While it is feasible to achieve concentrations of $1 \mathrm{mM}$ in patients [23], these concentrations are insufficient for single agent consideration and combination approaches which require lower concentrations of inhibitors are more likely to be beneficial.

The final target of the glycolytic pathway examined was $\mathrm{LDH}$, a tetramer of A and B subunits that catalyses the reduction of pyruvate to lactate coupled with NADH oxidation. NHI-1 was found to be a much more potent inhibitor than Oxamic acid. Breast and ovarian cancer cells had a similar response to Oxamic acid (Table 1). NHI-1 has been shown to produce synergistic activity when used in combination with gemcitabine in pancreatic cancer cell line models [27] and it may be that combination with cytotoxic drugs would be worth exploring within breast and ovarian cancer models.

The mechanism of action of these inhibitors was also investigated using flow cytometric analysis of treated cells stained with FITC-conjugated Annexin V and Propidium Iodide. Annexin V is a calcium dependent protein that binds to phosphatidylserine when exposed to the extracellular membrane of apoptotic cells. The viability dye PI is excluded from the intact cell membrane of viable cells. With this staining it is possible to distinguish between early apoptotic (Annexin V positive), late apoptotic (Annexin V and PI positive) and necrotic cells (PI positive). Evidence was obtained that all 9 of these inhibitors induce apoptosis. After a $48 \mathrm{~h}$ treatment all of them caused an induction of both early and late apoptosis (Figures 5a, 5b), consistent with targeting a common pathway. 
The expression levels of the glycolytic targets did not vary markedly in this panel of cell lines (Supplementary Figure 1) and no clear association between expression level and inhibitor response was apparent. We observed though that sensitivity to STF31 (GLUT1 inhibitor) and Oxamic acid (LDHA inhibitor) correlated significantly with the proliferation rate of the cell lines (Figure 6B). The differential effect of these compounds to the various cell lines can be explained by the difference in their growth rate. The most rapidly growing cell lines were found to be more sensitive to these compounds and these are likely to be more dependent on glycolysis for the production of energy and the metabolic intermediates needed for the biosynthesis of macromolecules and for that reason more sensitive to the glycolytic inhibitors.

Seven inhibitors demonstrated a correlation in their $\mathrm{IC}_{50}$ values in the panel of cell lines and these were Phloretin, Quercetin, 3BP, 3PO, DCA, NHI-1 and Oxamic acid. This would be consistent with their possessing a common mechanism of action i.e. inhibition of the glycolysis pathway. The two remaining inhibitors, STF31 and WZB117, did not correlate and it is feasible that inhibition of other (non-glycolytic pathway) targets may be responsible for their actions. Certainly, for STF31, a recent report has indicated that it can also inhibit nicotinamide phosphoribosyltransferase (NAMPT) which may contribute to its growth inhibitory activity [43].

Recently, there has been an increasing interest in the anti-proliferative effects of metformin. This widely prescribed antidiabetic drug, because of its low toxicity profile and its established efficacy to target metabolism, has attracted a great deal of attention. A considerable volume of literature has associated metformin with a decreased cancer risk and in addition metformin has been shown in many cases to increase sensitivity to chemotherapy [28, 29]. Currently metformin is undergoing several clinical trials in various cancer types as monotherapy or in combination with other drugs [28]. It has been shown to enhance cisplatin and paclitaxel efficacy in endometrial cancer cells [44] as well as cisplatin efficacy in ovarian cancer cells in vivo inhibiting also metastasis in the lung [45]. In another study Iliopoulos et al. showed a synergistic effect between metformin and Doxorubicin in a xenograft model using prostate and lung cancer cells [46]. Regarding glycolytic inhibitors two separate research groups, Sahra et al. in 2010 and Cheong et al. in 2011, demonstrated a synergistic effect between metformin and 2-deoxyglucose (2DG) in prostate cancer cells and mouse xenograft models respectively [47, 48]. Moreover in 2014 Choi et al. reported that DCA enhanced metformin potency in inducing cell death in HeLa cells [49].

Encouraged by promising evidence in previous studies we hypothesised that targeting two energy pathways simultaneously; the glycolytic pathway and mitochondrial oxidative phosphorylation, could result in greater energy depletion and enhance cell death of cancer cells. The selected cell line for combination experiments was the triple negative MDA-MB-231. These tumors are considered aggressive and invasive and have limited treatment options [50]. In addition this cell line lacks the functional tumor suppressor gene LKB1 [51]. This is an upstream kinase responsible for the activation of AMPK and is considered important for metformin's antitumor effect [29]. Our results are in agreement with findings from Zordoky et al. which showed that MDA-MB-231 cells are sensitive to metformin even though they are LKB1 deficient [51]. In terms of the culture conditions it should be mentioned that these experiments were contacted in $5.56 \mathrm{mM}$ glucose medium equivalent to physiological serum glucose levels, taking into consideration findings from previous studies indicating dependence of metformin's action on glucose availability $[49,51]$. We provide evidence of a synergistic interaction between STF31 and metformin as well as between Oxamic acid and metformin (Figure 7A). The CI values generated for both combinations were lower than 0.8 and indicate synergy. The concentrations of 3 and $4 \mathrm{mM}$ Metformin tested are relatively high but millimolar concentrations of the drug have been demonstrated to be achievable in vivo as the drug, being stable and not metabolized, can accumulate in tissues at much higher concentrations than in the blood [52]. These findings suggest a potential strategy for triple negative breast cancer treatment.

A key objective of this study was to investigate the sensitivity to the glycolytic inhibitors under varying levels of hypoxia. A published report of a series of normal and malignant breast tissues had indicated a median oxygen level of $8.6 \% \mathrm{O}_{2}$ in normal breast tissue $(n=16)$ compared to a median value of $4 \% \mathrm{O}_{2}$ in a series $(n=15)$ of malignant breast cancers [31]. Multiple measurements obtained within individual breast cancers demonstrated values varying between 0 and $13 \% \mathrm{O}_{2}$ indicating the diversity and mixture of differentially oxygenated populations that co-exist within individual tumors [31]. To test sensitivity, two representative breast cancer cell lines were selected. Dependence on glycolysis was examined over a range of oxygen levels varying from $21 \%$ to $0.5 \% \mathrm{O}_{2}$ and both cell lines examined were more sensitive to all glycolytic inhibitors at $21 \% \mathrm{O}_{2}$ conditions.

Previous studies investigating these inhibitors in normoxic and hypoxic conditions against other cancer cell lines have demonstrated widely contrasting results with some studies suggesting enhanced activity under normoxic conditions, other studies suggesting enhanced activity under hypoxic conditions and the majority of studies showing equivalent activity or minimally changed activity under both normoxic and hypoxic conditions [53-59]. For example, Phloretin is equally effective under normoxic and hypoxic conditions against the SW620 colon and K562 leukemia cell lines [53] while WZB117 is more effective against hypoxic than normoxic cells [14]. $3 \mathrm{BP}$ has previously been shown to be minimally more 
cytotoxic under hypoxic conditions [54-56] than normoxic conditions although the effects in these studies were very modest and are not dissimilar to other studies which indicate no difference between normoxia and hypoxia [57]. The LDH inhibitor NHI-1 is more effective in hypoxic than normoxic systems [27]. In contrast, several studies have shown that DCA is more cytotoxic in normoxic than hypoxic conditions [58, 59].

Increased dependency under hypoxic conditions might arise through up-regulation of the drug target providing a greater stimulus in cells hence its blockade might be more effective. Equally, increased drug target might also require more inhibitor to block its efficacy and furthermore other pathway components will also be up-regulated by hypoxia, requiring more drug to produce inhibition compared to normoxic conditions. The modulation of the drug targets was examined under these varying oxygen conditions and of the five targets examined, PFKFB3 and PDHK1 were up-regulated under hypoxic conditions in both cancer cell lines, while Hexokinase II and LDHA were up-regulated only in MCDF-7 cells at $0.5 \% \mathrm{O}_{2}$. Therefore relative resistance to the compounds at low $\mathrm{O}_{2}$ levels could be attributed at least in part to increased expression of the targets.

Another factor that should be taken into consideration is that cells grow more slowly in low $\mathrm{O}_{2}$ concentration and this might contribute to the decreased sensitivity to the compounds. There were significant associations for most of the compounds between growth rate and drug potency (i.e. $\mathrm{IC}_{50}$ ) across the panel of cell lines (Supplementary Table 3).

Together, these data indicate that inhibition of glycolysis is associated with growth inhibition in these breast and ovarian cancer cell lines. Combination of glycolytic inhibitors with metformin is proposed as a promising strategy for triple negative breast cancer treatment. Variation in oxygen levels between 0.5 and $7 \%$ has a relatively small effect on the efficacy of the inhibitors however these compounds are, in general, more effective at $21 \% \mathrm{O}_{2}$ which appears to correlate with an increased growth rate. We are currently assessing the effects of these inhibitors in combination with various cytotoxic and targeted therapies to assess how these might integrate with established therapies.

\section{MATERIALS AND METHODS}

\section{Cell culture and inhibitors}

A panel of eight cell lines was used; four breast cancer (MCF-7, MDA-MB-231, HBL100 and BT549) and four ovarian cancer cell lines (OVCAR5, TOV112D, OVCAR3, CAOV3). Key features of the cell lines are summarised in Supplementary Table 1. All cell lines were authenticated utilizing Short Tandem Repeat (STR) profiling. They were maintained in Dulbecco's Modified
Eagle Medium without HEPES modification (DMEM 31885-023, Invitrogen), including low glucose (5.56 mM), sodium pyruvate $(110 \mathrm{mg} / \mathrm{L})$ and L-glutamine $(3.97 \mathrm{mM})$. The medium was supplemented with $10 \%$ fetal calf serum and $1 \%$ penicillin-streptomycin. The cells were incubated in a humidified incubator at $37^{\circ} \mathrm{C}$ with $5 \% \mathrm{CO}_{2}$. They were grown in $\mathrm{T} 175 \mathrm{~cm}^{3}$ culture flasks, until reaching approximately $70-80 \%$ confluence, and were sub-cultured as follows. Medium was removed and cells were washed with phosphate buffered saline (PBS). Trypsin was used to cause cell detachment. Medium containing serum was added to neutralize the enzyme and cells were pelleted at $400 \mathrm{G}$ for $5 \mathrm{~min}$. Finally, cells were resuspended in media and passaged into fresh flasks or dishes (ratio 1:10). When necessary, cells were counted using a Neubauer hemocytometer. All procedures were performed under sterile conditions in a Laminar Air Flow hood. Hypoxia experiments were conducted at $37^{\circ} \mathrm{C}$ with $5 \% \mathrm{CO}_{2}$ and $7 \%, 2 \%$ or $0.5 \% \mathrm{O}_{2}$ using the H35 Hypoxystation (Don Whitley Scientific, Shipley, UK). Prior to hypoxia experiments, cells were allowed to adapt to each oxygen level for at least 5 days.

Phloretin, Quercetin, 3BP, DCA and Oxamic acid were obtained from Sigma Aldrich. STF31 and Metformin were obtained from Tocris Bioscience, WZB117 and 3PO from Merck Millipore and NHI-1 from Mercachem. Stock solutions of compounds were prepared in DMSO except for WZB117 which was dissolved in ethanol and DCA, Oxamic acid, 3BP and Metformin in PBS.

\section{Sulphorhodamine B assay (SRB)}

The SRB assay is a cell density assay based on the measurement of cellular protein content [60]. Cells (0.5 $2 \times 10^{3}$ cells/well, depending on the proliferation rate of each cell line) were seeded in 96-well plates. Forty-eight hours later, cells were treated with or without the indicated concentration of the inhibitors. A 10-point dilution series with 1:2 steps in six replicates was performed. For the compounds dissolved in dimethylsulphoxide (DMSO) or ethanol, a constant DMSO/ ethanol concentration was used across the whole concentration- response curve. After a five day incubation period, cell monolayers were fixed with cold $25 \%$ trichloroacetic acid (Sigma) and stained with the SRB dye solution (Sigma). Unbound excess dye was removed by $1 \%$ acetic acid washes. The protein-bound stain was solubilized in 10mM Tris buffer solution ( $\mathrm{pH} 10.5)$. Finally absorbance was measured at $540 \mathrm{~nm}$ using a microplate reader (BP800, Biohit Health Care). Measurements were corrected for background absorbance and presented as percentage of absorbance in untreated cells

The half maximal inhibitory concentration $\left(\mathrm{IC}_{50}\right)$ was used as a measure of the effectiveness of each compound. It indicates the concentration needed to reduce cell number by half. Sigmoidal concentration response curves were fitted and the $\mathrm{IC}_{50}$ values were defined using the $\mathrm{XL}$ fit tool within the Microsoft Excel. 
For drug interaction studies a range of 7 different concentrations of glycolytic inhibitors was used in combination with a fixed concentration of metformin (around the $\mathrm{IC}_{20}$ ). Both drugs were administered at the same time and the SRB assay was performed after a three day treatment. Data were analysed using the Calcusyn Software generating combination index values (CI) for each single combination point [61].

\section{Glucose uptake assay}

Cells were seeded in 12 -well plates at $1 \times 10^{5}$ to $2 \times 10^{5}$ cells per well. The following day, cells were treated with or without the indicated concentration of inhibitor. The concentrations used for each compound were determined based on the corresponding $\mathrm{IC}_{50}$ values derived from the SRB assays. Culture media was collected at $24 \mathrm{~h}$. Glucose remaining in the media was measured using the Amplex Red Glucose/Glucose Oxidase Assay Kit (Invitrogen), according to the manufacturer's instructions. Samples were diluted 1:50 in 1xReaction Buffer provided in the kit. A 96-well plate format with triplicates was used. After a 30 min incubation period with the reaction reagent solution, protected from light, absorbance was measured at $540 \mathrm{~nm}$ using the microplate reader. Measurements were corrected for background absorbance, subtracting the value derived from the no-glucose control [62].

\section{Lactate assay}

Lactate was measured in the same samples as used for the glucose assay, as described above. Lactate produced in the media was measured using the Lactate Assay Kit (Trinity Biotech), according to the manufacturer's instructions. A 96-well plate format with triplicates was used. $2 \mu \mathrm{l}$ of sample was added to the wells followed by $200 \mu \mathrm{l}$ of lactate reagent. The reagent was used as a $50 \%$ solution in distilled water. Plates were incubated in the dark for $7 \mathrm{~min}$ and absorbance was measured at $540 \mathrm{~nm}$ using the microplate reader. Measurements were corrected for background absorbance, subtracting the value derived from the no-lactate control [63].

\section{Flow cytometry analysis}

Detection of compound-induced cell death was carried out by dual staining with FITC-conjugated Annexin $\mathrm{V}$ and Propidium Iodide (PI) followed by flow cytometry. Briefly, 3 x $10^{5}$ cells were seeded in 6-well plates and the following day they were treated with or without the indicated concentration of inhibitor. After a $48 \mathrm{~h}$ treatment, cells were harvested and stained using the FITC Annexin V Apoptosis Detection Kit I (BD Pharmingen) according to the manufacturer's instructions. Data acquisition and analysis of 30,000 events for each sample was performed using the flow cytometer BD Accuri C6 (BD Biosciences). Annexin $\mathrm{V}$ single positive cells were identified as early apoptotic, while cells both Annexin V and PI positive were identified as end stage apoptotic cells and PI positive cells as necrotic.

\section{Western blotting}

Cells were seeded in cell culture dishes and, when approximately $80 \%$ confluent, were washed with ice cold PBS and then treated with ice cold isotonic lysis buffer (50mM Tris pH7.5, 5 mM EGTA pH8.5, $150 \mathrm{mM}$ $\mathrm{NaCl}, 1$ "Complete Protease Inhibitor Tablet" (Roche), $100 \mu l$ Phosphatase Inhibitor Cocktail 2 (Sigma), 100 $\mu 1$ Phosphatase Inhibitor Cocktail 3 (Sigma), $50 \mu$ l Aprotinin (Sigma), $100 \mu 1$ Triton-X 100 (Sigma)). Subsequently cells were scraped and after centrifugation lysate supernatant was collected and stored at $-70^{\circ} \mathrm{C}$. The Bicinchoninic Acid Assay (BCA) was performed to determine lysate protein concentration and absorbance was measured at 540nm using a microplate reader. Sodium dodecyl sulphate polyacrylamide gel electrophoresis (SDSPAGE) was performed to separate proteins according to their molecular weight. Following electrophoresis, proteins were transferred onto a methanol-activated Immobilon-P polyvinylidene fluoride (PVDF) Transfer Membrane (Immobilon) using the Bio-Rad Protean Transfer Cell equipment. Transfer was performed at $100 \mathrm{~V}$ for $1 \mathrm{~h}$ in ice-cold Tris-Glycine transfer buffer at $4^{\circ} \mathrm{C}$. After transfer the membrane was blocked for $1 \mathrm{~h}$ at RT, in 1:1 PBS/Odyssey Blocking Buffer to prevent nonspecific binding. Following blocking, the membrane was incubated in primary antibody solution at $4^{\circ} \mathrm{C}$ overnight. The following primary antibodies were used: GLUT1 (07-1401; Millipore), HKII (2867; CST), PFKFB3 (13123; CST), PDHK1 (3820; CST), LDHA (3582; CST) and $\alpha$-Tubulin (ab7291; Abcam). As antibody diluent, PBS/Odyssey Blocking Buffer or $5 \% \mathrm{w} / \mathrm{v}$ bovine serum albumin (BSA, Sigma) in $1 \mathrm{X}$ PBS containing $0.1 \%$ Tween-20 were used. After primary antibody incubation, the membrane was washed with PBS- $0.1 \%$ Tween 20 , to remove excess antibody. Secondary fluorescent antibody (anti-rabbit IR Dye 800CW (926-32211; Odyssey) and anti-mouse IR Dye 680LT (926-68020; Odyssey)) were employed, raised against the species of the primary antibody and diluted in PBS/Odyssey Blocking Buffer containing $0.001 \%$ SDS. Incubation was performed for $45 \mathrm{~min}$ at room temperature, protected from light. Finally the membrane was washed with PBS-0.1\% Tween 20 . Visualization of proteins was achieved by scanning on the Odyssey Infrared Imaging System (Licor). This machine is equipped with two infrared channels for direct fluorescence detection allowing two separate targets to be probed simultaneously. 


\section{Statistics}

To evaluate the significance of differences between treated samples and untreated controls, ANOVA followed by the Tukey-Kramer Multiple Comparisons Test was used. To correlate the expression of the glycolytic enzymes in the panel of the eight cancer cell lines with their sensitivity to the inhibitors the non-Parametric Spearman correlation test was performed. Statistical tests were undertaken using GraphPad software.

\section{ACKNOWLEDGMENTS}

We thank Elisabeth Freyer (Flow Cytometry Facility IGMM, University of Edinburgh UK) for assistance with the FACs analysis.

\section{CONFLICTS OF INTEREST} interests.

The authors declare that they have no competing

\section{FINANCIAL SUPPORT}

We are grateful to Medical Research Scotland for support of this study.

\section{REFERENCES}

1. Hsu PP, Sabatini DM. Cancer cell metabolism: Warburg and beyond. Cell. 2008; 134:703-707.

2. Heiden MGV, Cantley LC, Thompson CB. Understanding the warburg effect: The metabolic requirements of cell proliferation. Science. 2009; 324:1029-1033.

3. Hanahan D, Weinberg RA. Hallmarks of cancer: The next generation. Cell. 2011; 144:646-674.

4. Zhao Y, Butler EB, Tan M. Targeting cellular metabolism to improve cancer therapeutics. Cell Death and Disease. 2013; 4:e532.

5. Tennant DA, Durán RV, Gottlieb E. Targeting metabolic transformation for cancer therapy. Nature Reviews Cancer. 2010; 10:267-277.

6. Madhok BM, Yeluri S, Perry SL, Hughes TA, Jayne DG. Targeting glucose metabolism: An emerging concept for anticancer therapy. American Journal of Clinical Oncology: Cancer Clinical Trials. 2011; 34:628-635.

7. Martin HJ, Kornmann F, Fuhrmann GF. The inhibitory effects of flavonoids and antiestrogens on the Glut l glucose transporter in human erythrocytes. Chemico-Biological Interactions. 2003; 146:225-235.

8. Romano B, Pagano E, Montanaro V, Fortunato AL, Milic N, Borrelli F. Novel insights into the pharmacology of flavonoids. Phytotherapy Research. 2013; 27:1588-1596.
9. Kim MS, Kwon JY, Kang NJ, Lee KW, Lee HJ. Phloretin induces apoptosis in H-Ras MCF10A human breast tumor cells through the activation of p53 via JNK and p38 mitogen-activated protein kinase signaling. Ann NY Acad Sci. 2009; 1171:479-483.

10. Wu CH, Ho YS, Tsai CY, Wang YJ, Tseng H, Wei PL, Lee $\mathrm{CH}$, Liu RS, Lin SY. In vitro and in vivo study of phloretin-induced apoptosis in human liver cancer cells involving inhibition of type II glucose transporter. International Journal of Cancer. 2009; 124:2210-2219.

11. Zhang $\mathrm{H}$, Zhang $\mathrm{M}$, Yu L, Zhao Y, He N, Yang X. Antitumor activities of quercetin and quercetin-5', 8-disulfonate in human colon and breast cancer cell lines. Food and Chemical Toxicology. 2012; 50:1589-1599.

12. Kim HS, Wannatung T, Lee S, Yang WK, Chung SH, Lim JS, Choe W, Kang I, Kim SS, Ha J. Quercetin enhances hypoxia-mediated apoptosis via direct inhibition of AMPK activity in HCT116 colon cancer. Apoptosis. 2012; 17:938-949.

13. Chan DA, Sutphin PD, Nguyen P, Turcotte S, Lai EW, Banh A, Reynolds GE, Chi JT, Wu J, Solow-Cordero DE, Bonnet M, Flanagan JU, Bouley DM, et al. Targeting GLUT1 and the Warburg effect in renal cell carcinoma by chemical synthetic lethality. Science Translational Medicine. 2011; 3:94ra70.

14. Liu Y, Cao Y, Zhang W, Bergmeier S, Qian Y, Akbar H, Colvin R, Ding J, Tong L, Wu S, Hines J, Chen X. A smallmolecule inhibitor of glucose transporter 1 downregulates glycolysis, induces cell-cycle arrest, and inhibits cancer cell growth in vitro and in vivo. Molecular Cancer Therapeutics. 2012; 11:1672-1682.

15. Cardaci S, Desideri E, Ciriolo MR. Targeting aerobic glycolysis: 3-Bromopyruvate as a promising anticancer drug. Journal of Bioenergetics and Biomembranes. 2012; 44:17-29.

16. Pedersen PL. 3-Bromopyruvate (3BP) a fast acting, promising, powerful, specific, and effective "small molecule" anti-cancer agent taken from labside to bedside: Introduction to a special issue. Journal of Bioenergetics and Biomembranes. 2012; 44:1-6.

17. Clem B, Telang S, Clem A, Yalcin A, Meier J, Simmons A, Rasku MA, Arumugam S, Dean WL, Eaton J, Lane A, Trent JO, Chesney J. Small-molecule inhibition of 6-phosphofructo-2-kinase activity suppresses glycolytic flux and tumor growth. Molecular Cancer Therapeutics. 2008; $7: 110-120$.

18. Granchi C, Fancelli D, Minutolo F. An update on therapeutic opportunities offered by cancer glycolytic metabolism. Bioorganic and Medicinal Chemistry Letters. 2014; 24:4915-4925.

19. Wong JYY, Huggins GS, Debidda M, Munshi NC, De Vivo I. Dichloroacetate induces apoptosis in endometrial cancer cells. Gynecologic Oncology. 2008; 109:394-402. 
20. Sun RC, Fadia M, Dahlstrom JE, Parish CR, Board PG, Blackburn AC. Reversal of the glycolytic phenotype by dichloroacetate inhibits metastatic breast cancer cell growth in vitro and in vivo. Breast Cancer Research and Treatment. 2010; 120:253-260.

21. Michelakis ED, Webster L, Mackey JR. Dichloroacetate (DCA) as a potential metabolic-targeting therapy for cancer. British Journal of Cancer. 2008; 99:989-994.

22. Michelakis ED, Sutendra G, Dromparis P. Metabolic Modulation of Glioblastoma with Dichloroacetate. Science translational medicine. 2010; 2:31ra34.

23. Garon EB, Christofk HR, Hosmer W, Britten CD, Bahng A, Crabtree MJ, Hong CS, Kamranpour N, Pitts S, Kabbinavar F, Patel C, Euw EV, Black A, et al. Dichloroacetate should be considered with platinum-based chemotherapy in hypoxic tumors rather than as a single agent in advanced non-small cell lung cancer. J Cancer Res Clin Oncol. 2014; 140:443-452.

24. Fiume L, Manerba M, Vettraino M, Di Stefano G. Impairment of aerobic glycolysis by inhibitors of lactic dehydrogenase hinders the growth of human hepatocellular carcinoma cell lines. Pharmacology. 2010; 86:157-162.

25. Fiume L, Vettraino M, Manerba M, Di Stefano G. Inhibition of lactic dehydrogenase as a way to increase the antiproliferative effect of multi-targeted kinase inhibitors. Pharmacological Research. 2011; 63:328-334.

26. Granchi C, Roy S, Giacomelli C, MacChia M, Tuccinardi T, Martinelli A, Lanza M, Betti L, Giannaccini G, Lucacchini A, Funel N, León LG, Giovannetti E, et al. Discovery of N-hydroxyindole-based inhibitors of human lactate dehydrogenase isoform A (LDH-A) as starvation agents against cancer cells. Journal of Medicinal Chemistry. 2011; 54:1599-1612.

27. Maftouh M, Avan A, Sciarrillo R, Granchi C, Leon LG, Rani R, Funel N, Smid K, Honeywell R, Boggi U, Minutolo F, Peters GJ, Giovannetti E. Synergistic interaction of novel lactate dehydrogenase inhibitors with gemcitabine against pancreatic cancer cells in hypoxia. British Journal of Cancer. 2014; 110:172-182.

28. Rizos CV, Elisaf MS. Metformin and cancer. European Journal of Pharmacology. 2013; 705:96-108.

29. Quinn BJ, Kitagawa H, Memmott RM, Gills JJ, Dennis PA. Repositioning metformin for cancer prevention and treatment. Trends in Endocrinology and Metabolism. 2013; 24:469-480.

30. Viollet B, Guigas B, Sanz Garcia N, Leclerc J, Foretz M, Andreelli F. Cellular and molecular mechanisms of metformin: An overview. Clinical Science. 2012; 122:253-270.

31. Vaupel P, Schienger K, Knoop C, Höckel M. Oxygenation of human tumors: Evaluation of tissue oxygen distribution in breast cancers by computerized $\mathrm{O} 2$ tension measurements. Cancer Research. 1991; 51:3316-3322.

32. Wenger RH. Cellular adaptation to hypoxia: O2-sensing protein hydroxylases, hypoxia-inducible transcription factors, and O2-regulated gene expression. FASEB Journal. 2002; 16:1151-1162.

33. Porporato PE, Dhup S, Dadhich RK, Copetti T, Sonveaux P. Anticancer targets in the glycolytic metabolism of tumors: A comprehensive review. Frontiers in Pharmacology. 2011; 2:49.

34. Pinheiro C, Sousa B, Albergaria A, Paredes J, Dufloth R, Vieira D, Schmitt F, Baltazar F. GLUT1 and CAIX expression profiles in breast cancer correlate with adverse prognostic factors and MCT1 overexpression. Histology and Histopathology. 2011; 26:1279-1286.

35. Kang SS, Chun YK, Hur MH, Lee HK, Kim YJ, Hong SR, Lee JH, Lee SG, Park YK. Clinical significance of glucose transporter 1 (GLUT1) expression in human breast carcinoma. Japanese Journal of Cancer Research. 2002; 93:1123-1128.

36. Younes M, Brown RW, Mody DR, Fernandez L, Laucirica R. GLUT1 expression in human breast carcinoma: Correlation with known prognostic markers. Anticancer Research. 1995; 15:2895-2898.

37. Jang SM, Han H, Jang KS, Jun YJ, Jang SH, Min KW, Chung MS, Paik SS. The glycolytic phenotype is correlated with aggressiveness and poor prognosis in invasive ductal carcinomas. Journal of Breast Cancer. 2012; 15:172-180.

38. Cantuaria G, Fagotti A, Ferrandina G, Magalhaes A, Nadji M, Angioli R, Penalver M, Mancuso S, Scambia G. GLUT-1 expression in ovarian carcinoma: Association with survival and response to chemotherapy. Cancer. 2001; 92:1144-1150.

39. Sato-Tadano A, Suzuki T, Amari M, Takagi K, Miki Y, Tamaki K, Watanabe M, Ishida T, Sasano H, Ohuchi N. Hexokinase II in breast carcinoma: A potent prognostic factor associated with hypoxia-inducible factor- $1 \alpha$ and Ki-67. Cancer Science. 2013; 104:1380-1388.

40. Suh DH, Kim MA, Kim H, Kim MK, Kim HS, Chung HH, Kim YB, Song YS. Association of overexpression of hexokinase II with chemoresistance in epithelial ovarian cancer. Clinical and Experimental Medicine. 2014; 14:345-353.

41. Buijs M, Vossen JA, Geschwind JFH, Ishimori T, Engles JM, Acha-Ngwodo O, Wahl RL, Vali M. Specificity of the anti-glycolytic activity of 3-bromopyruvate confirmed by FDG uptake in a rat model of breast cancer. Investigational New Drugs. 2009; 27:120-123.

42. Wintzell M, Löfstedt L, Johansson J, Pedersen AB, Fuxe J, Shoshan M. Repeated cisplatin treatment can lead to a multiresistant tumor cell population with stem cell features and sensitivity to 3-bromopyruvate. Cancer Biology and Therapy. 2012; 13:1454-1462.

43. Adams DJ, Ito D, Rees MG, Seashore-Ludlow B, Puyang X, Ramos AH, Cheah JH, Clemons PA, Warmuth M, Zhu P, Shamji AF, Schreiber SL. NAMPT Is the Cellular Target of STF-31-Like Small-Molecule Probes. ACS Chem Biol. 2014; 9:2247-2254. 
44. Dong L, Zhou Q, Zhang Z, Zhu Y, Duan T, Feng Y. Metformin sensitizes endometrial cancer cells to chemotherapy by repressing glyoxalase I expressionjog. Journal of Obstetrics and Gynaecology Research. 2012; 38:1077-1085.

45. Rattan R, Graham RP, Maguire JL, Giri S, Shridhar V. Metformin suppresses ovarian cancer growth and metastasis with enhancement of cisplatin cytotoxicity in Vivo. Neoplasia. 2011; 13:483-491.

46. Iliopoulos D, Hirsch HA, Struhl K. Metformin decreases the dose of chemotherapy for prolonging tumor remission in mouse xenografts involving multiple cancer cell types. Cancer Research. 2011; 71:3196-3201.

47. Sahra IB, Laurent K, Giuliano S, Larbret F, Ponzio G, Gounon P, Le Marchand-Brustel Y, Giorgetti-Peraldi S, Cormont M, Bertolotto C, Deckert M, Auberger P, Tanti JF, et al. Targeting cancer cell metabolism: The combination of metformin and 2-deoxyglucose induces p53-dependent apoptosis in prostate cancer cells. Cancer Research. 2010; 70:2465-2475.

48. Cheong JH, Park ES, Liang J, Dennison JB, Tsavachidou D, Nguyen-Charles C, Cheng KW, Hall H, Zhang D, Lu Y, Ravoori M, Kundra V, Ajani J, et al. Dual inhibition of tumor energy pathway by 2-deoxyglucose and metformin is effective against a broad spectrum of preclinical cancer models. Molecular Cancer Therapeutics. 2011; 10:2350-2362.

49. Choi YW, Lim IK. Sensitization of metformin-cytotoxicity by dichloroacetate via reprogramming glucose metabolism in cancer cells. Cancer Letters. 2014; 346:300-308.

50. Griffiths CL, Olin JL. Triple negative breast cancer: A brief review of its characteristics and treatment options. Journal of Pharmacy Practice. 2012; 25:319-323.

51. Zordoky BNM, Bark D, Soltys CL, Sung MM, Dyck JRB. The anti-proliferative effect of metformin in triple-negative MDA-MB-231 breast cancer cells is highly dependent on glucose concentration: Implications for cancer therapy and prevention. Biochimica et Biophysica Acta - General Subjects. 2014; 1840:1943-1957.

52. Wilcock C, Bailey CJ. Accumulation of metformin by tissues of the normal and diabetic mouse. Xenobiotica. 1994; 24:49-57.
53. Cao X, Fang L, Gibbs S, Huang Y, Dai Z, Wen P, Zheng X, Sadee W, Sun D. Glucose uptake inhibitor sensitizes cancer cells to daunorubicin and overcomes drug resistance in hypoxia. Cancer Chemotherapy and Pharmacology. 2007; 59:495-505.

54. Xu RH, Pelicano H, Zhou Y, Carew JS, Feng L, Bhalla KN, Keating MJ, Huang P. Inhibition of glycolysis in cancer cells: A novel strategy to overcome drug resistance associated with mitochondrial respiratory defect and hypoxia. Cancer Research. 2005; 65:613-621.

55. Cao X, Bloomston M, Zhang T, Frankel WL, Jia G, Wang B, Hall NC, Koch RM, Cheng H, Knopp MV, Sun D. Synergistic antipancreatic tumor effect by simultaneously targeting hypoxic cancer cells with HSP90 inhibitor and glycolysis inhibitor. Clinical Cancer Research. 2008; 14:1831-1839.

56. Gwak GY, Yoon JH, Kim KM, Lee HS, Chung JW, Gores GJ. Hypoxia stimulates proliferation of human hepatoma cells through the induction of hexokinase II expression. Journal of Hepatology. 2005; 42:358-364.

57. Xiao H, Li S, Zhang D, Liu T, Yu M, Wang F. Separate and concurrent use of 2-deoxy-D-glucose and 3-bromopyruvate in pancreatic cancer cells. Oncol Rep. 2013; 29:329-334.

58. Anderson KM, Jajeh J, Guinan P, Rubenstein M. In vitro effects of dichloroacetate and $\mathrm{CO} 2$ on hypoxic HeLa cells. Anticancer Research. 2009; 29:4579-4588.

59. Shahrzad S, Lacombe $\mathrm{K}$, Adamcic U, Minhas $\mathrm{K}$, Coomber BL. Sodium dichloroacetate (DCA) reduces apoptosis in colorectal tumor hypoxia. Cancer Letters. 2010; 297:75-83.

60. Vichai V, Kirtikara K. Sulforhodamine B colorimetric assay for cytotoxicity screening. Nat. Protocols. 2006; $1: 1112-1116$.

61. Irene V, Bijnsdorp EG, Godefridus J. Peters, Analysis of Drug Interactions, in Cancer Cell Culture, Methods and Protocols, I.A. Cree, Editor 2011: Humana Press. p. $421-434$.

62. http://products.invitrogen.com/ivgn/product/A22189.

63. http://www.trinitybiotech.com/ClinicalChemistry/Pages/ ProductDetails.aspx?ProductNumber $=735-10 \&$ Filter $=$ *735-10*. 